
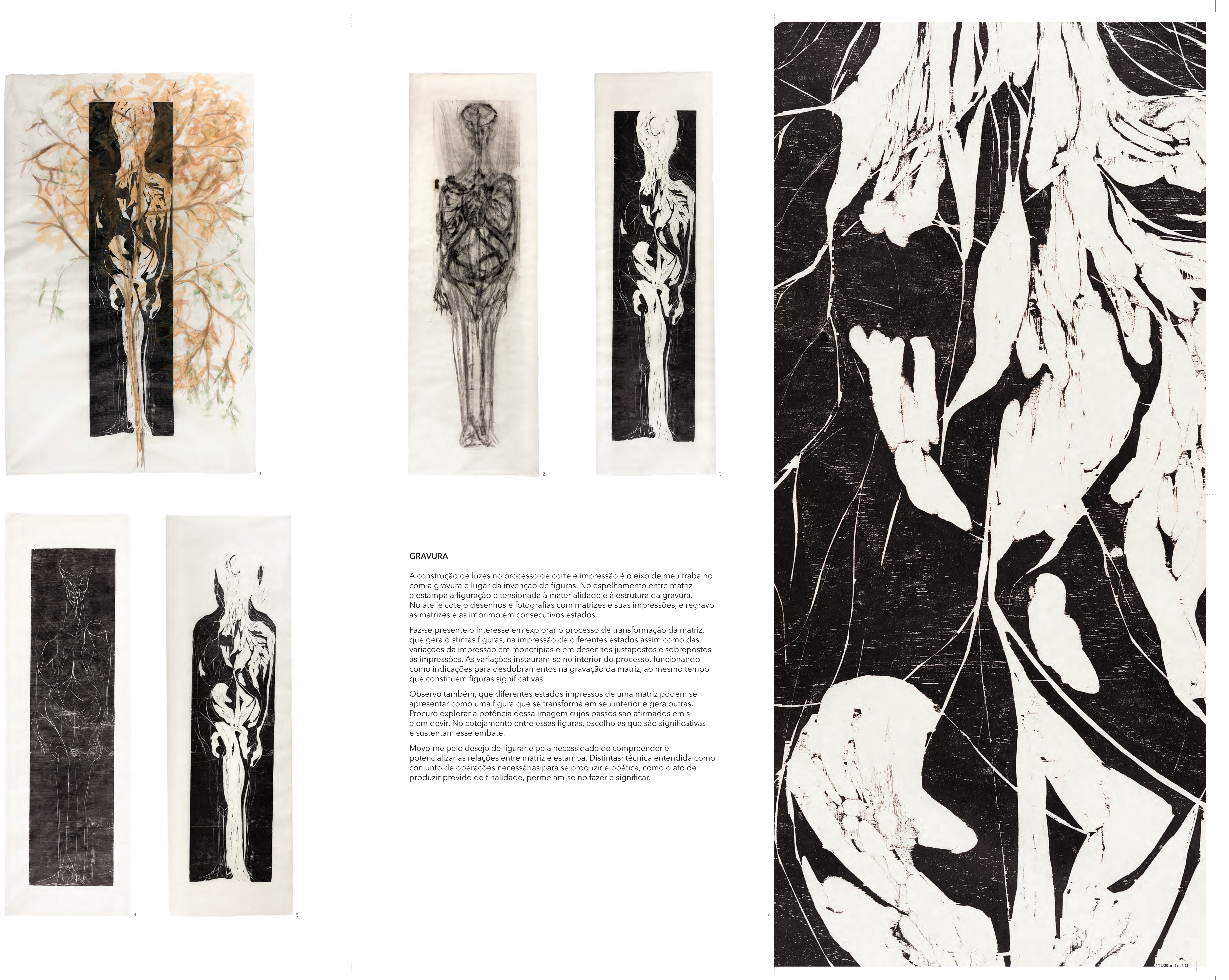

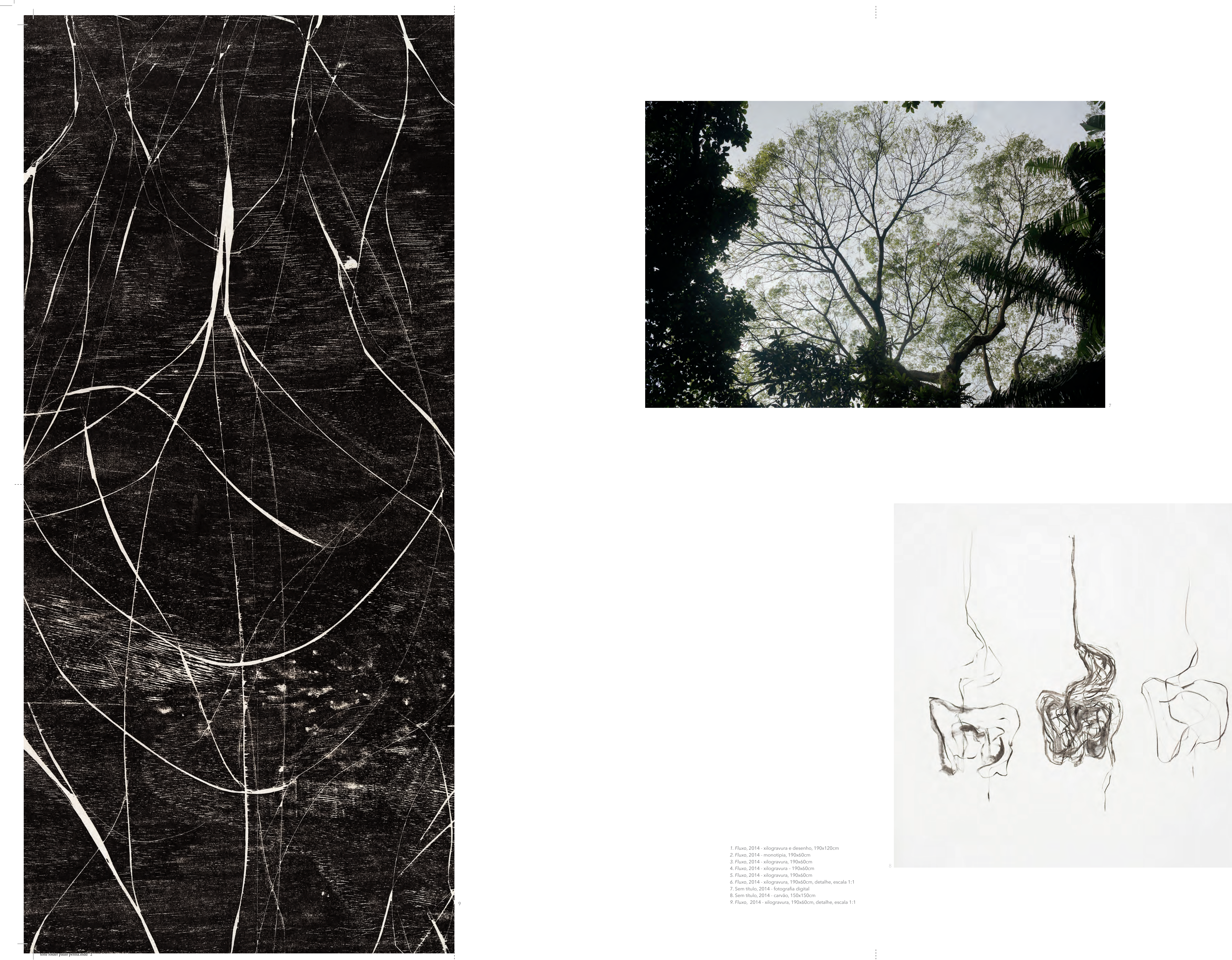

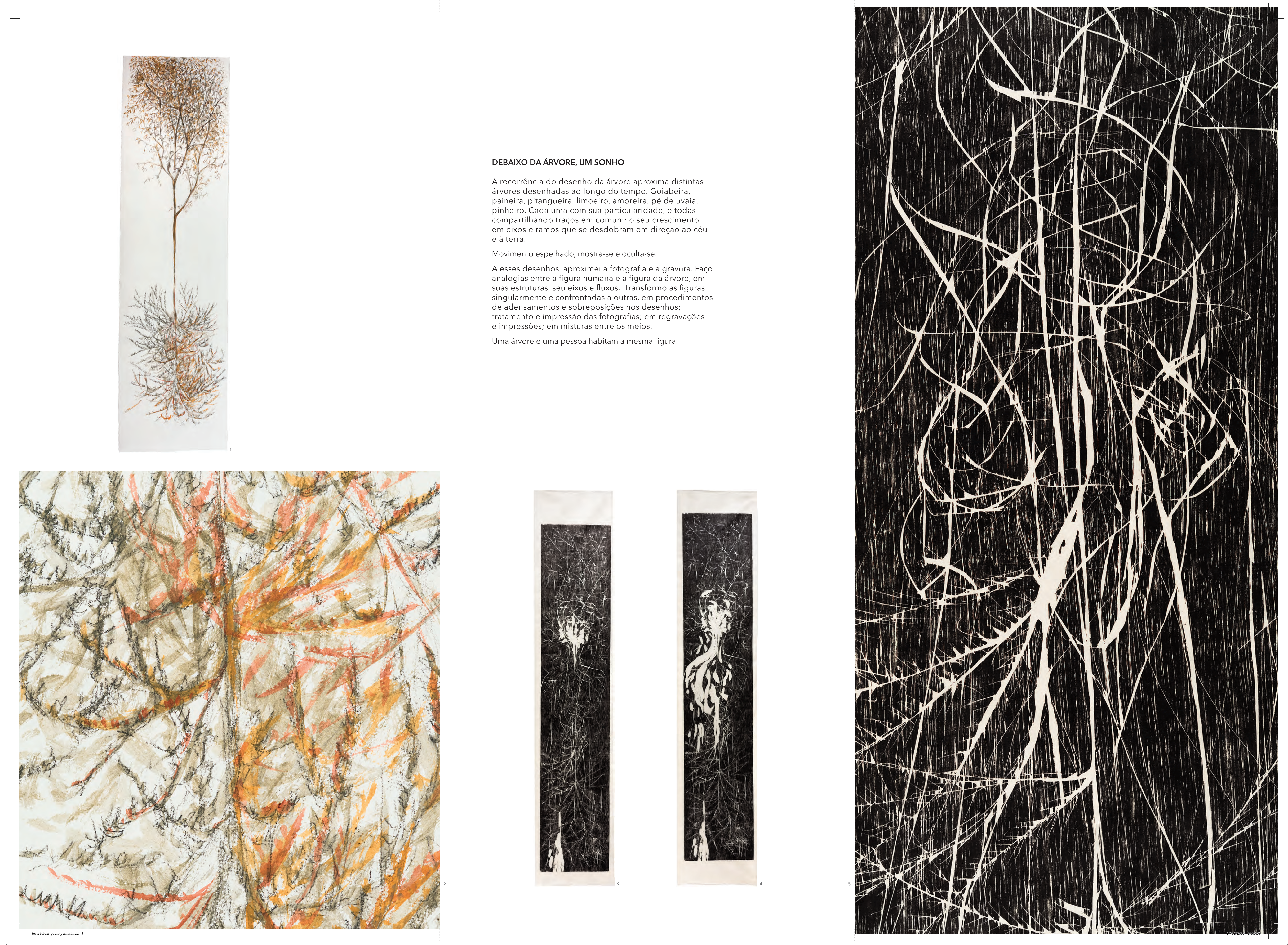



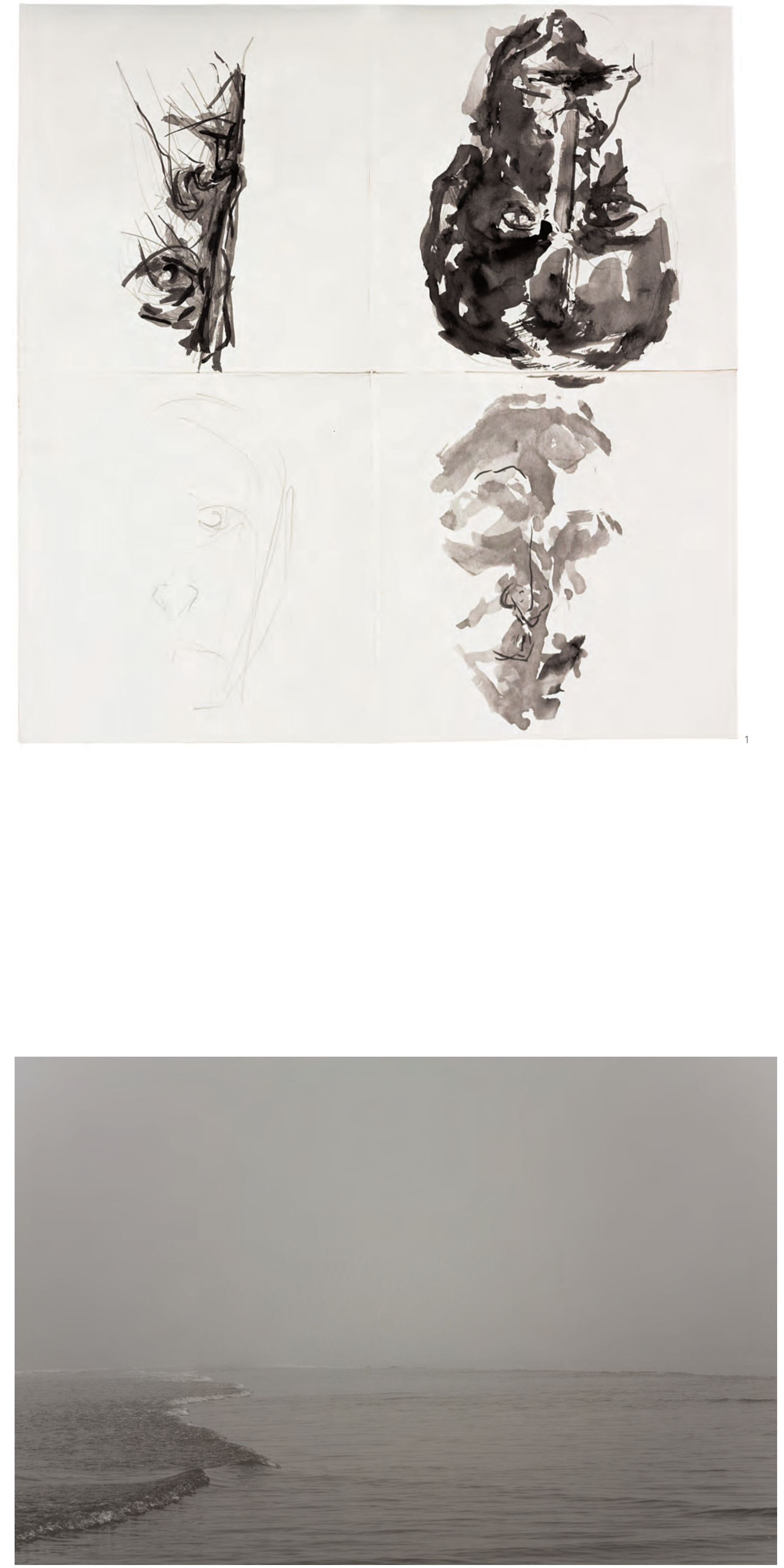

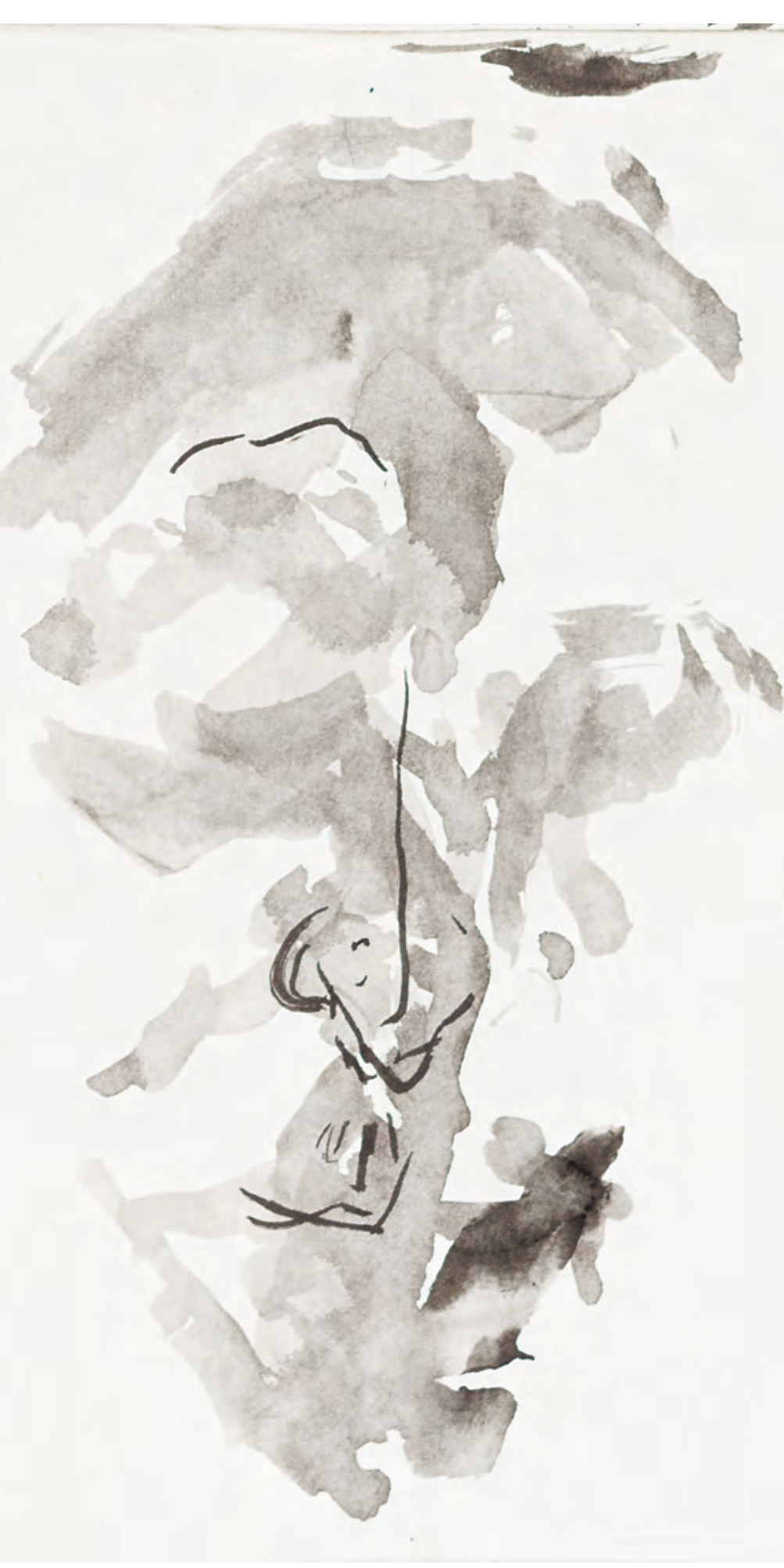

Pés sobre a areia molhada a água gelada cobrindo meu corpo até a barriga.

vada através da lente

desde a infáncia, revisto em suas transtormaçoes e

Em um fenómeno em constante transformaçẫo, procuro

estabelecer vínculos e associar diferentes experiências no

Oempo, atraves de inagens.

O devaneio é interrompido pelo choque de uma ond

Procuro e observo a crianca que brinca por togtato valo

a olhar pela lente, um pássaro sobe pela garganta.
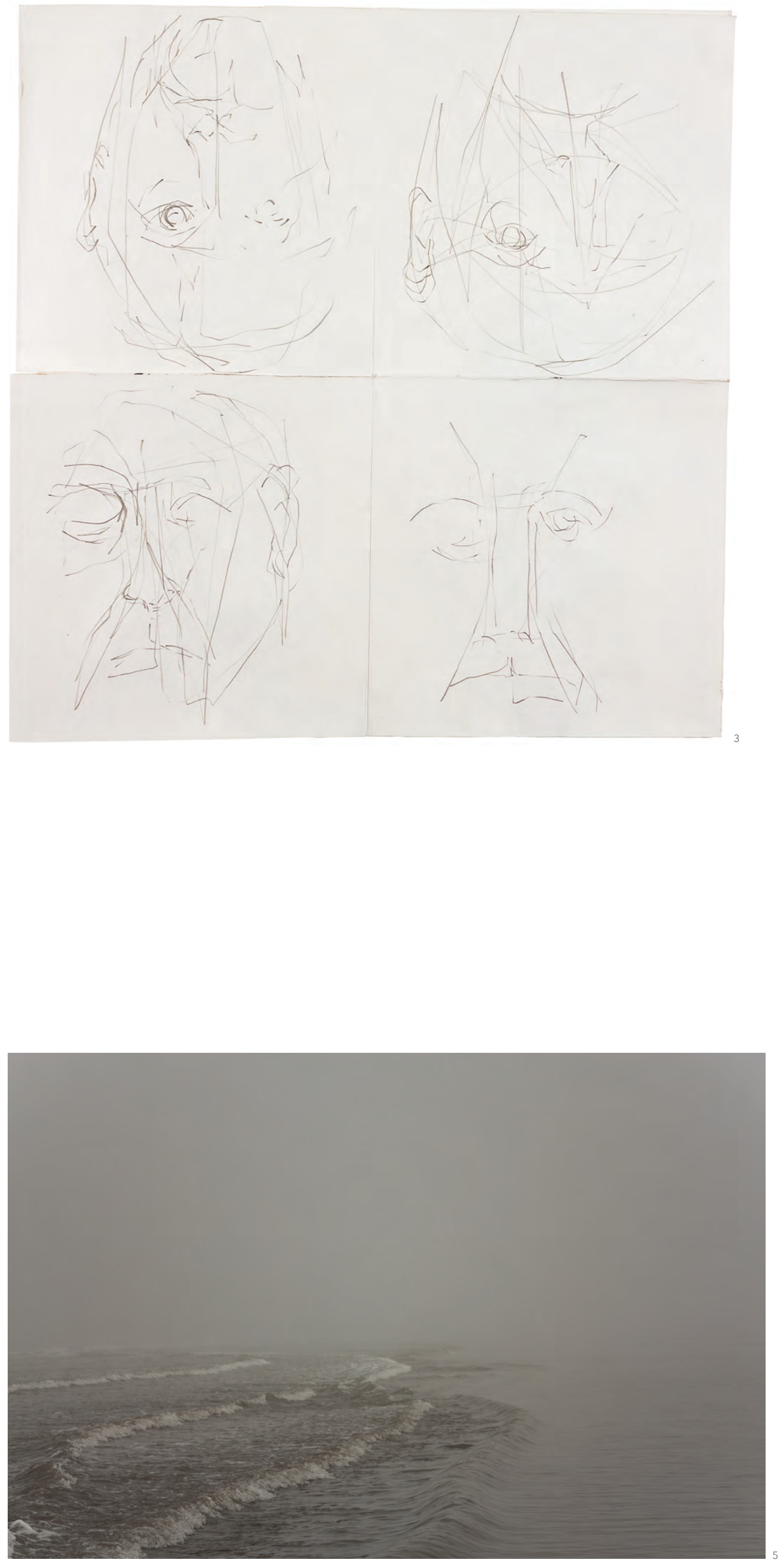


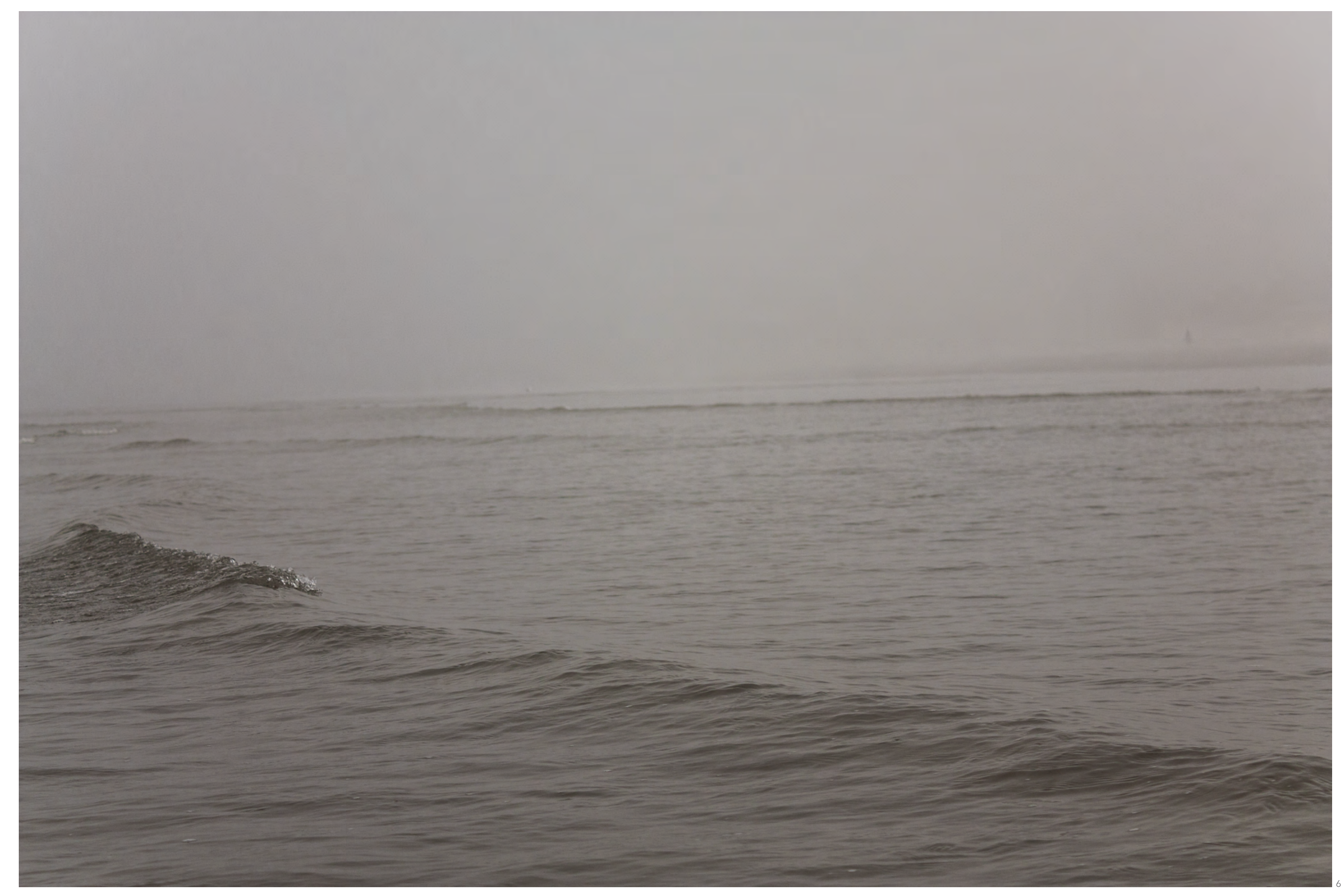



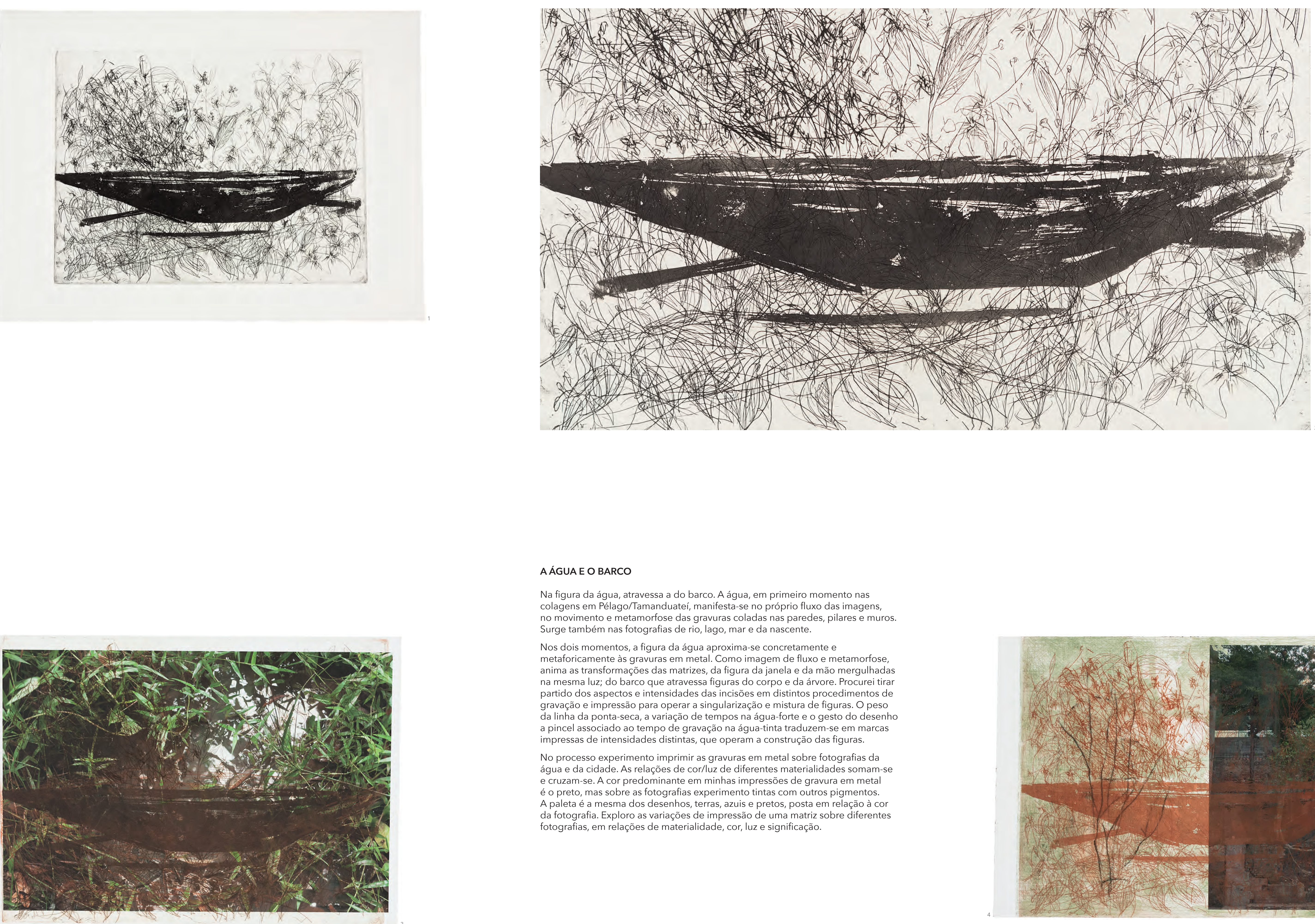

Na figura da água, atravessa a do barco. A água, em primeiro momento nas colagens em Pélago/Tamanduateí, manifesta-se no próprio fluxo das imagens, Surge também nas fotografias de rio, lago, mar e da nascente.

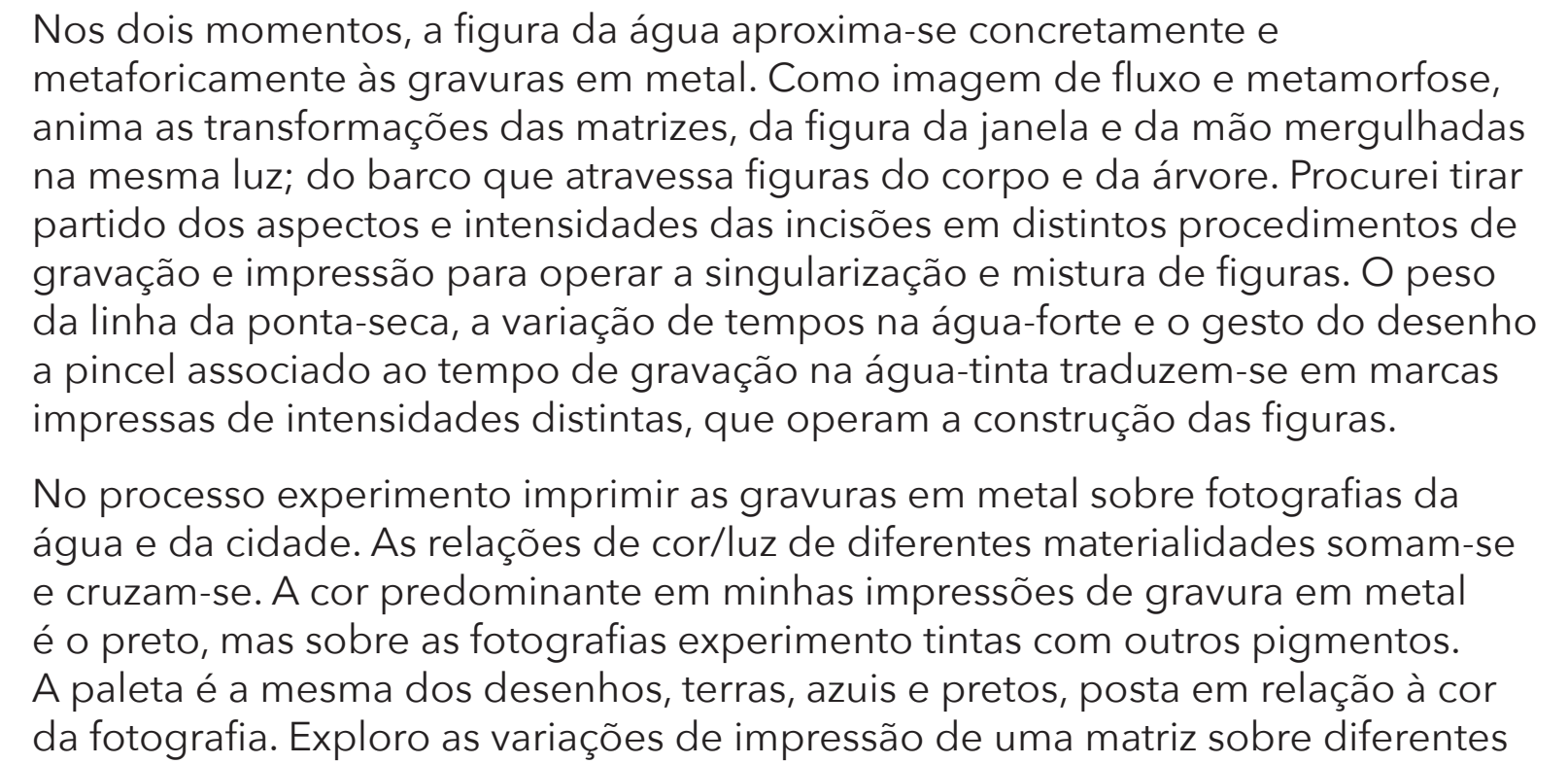
A paleta e mesma dos desenhos, terras, azulis e pretos, posta em relacãa à cor
da fotografia. Exploro as variaçoes de impressão de uma matriz sobre diferentes fotogratias, em relaçoes de materialididade, cor, luz e signnificaçāo.

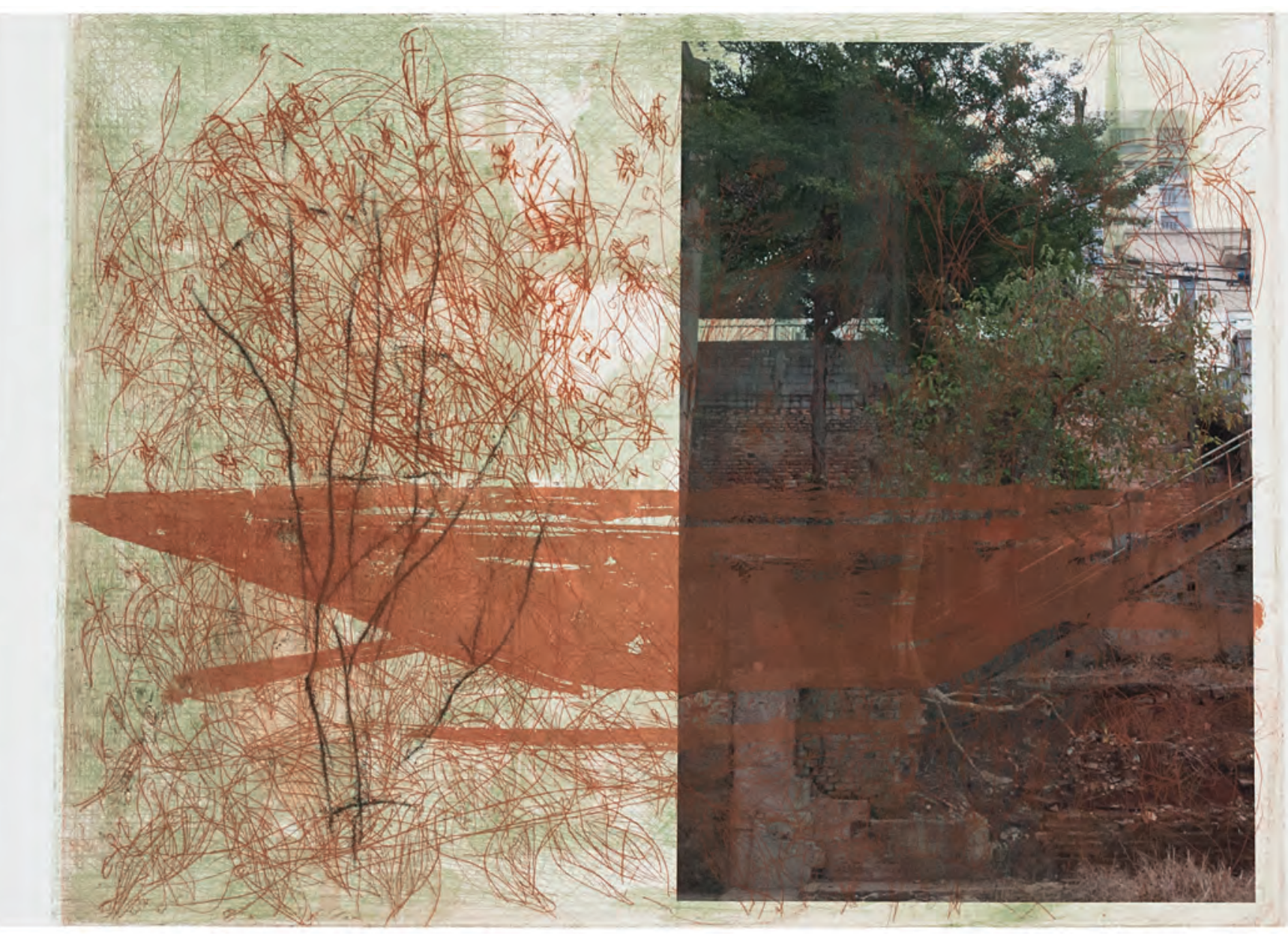




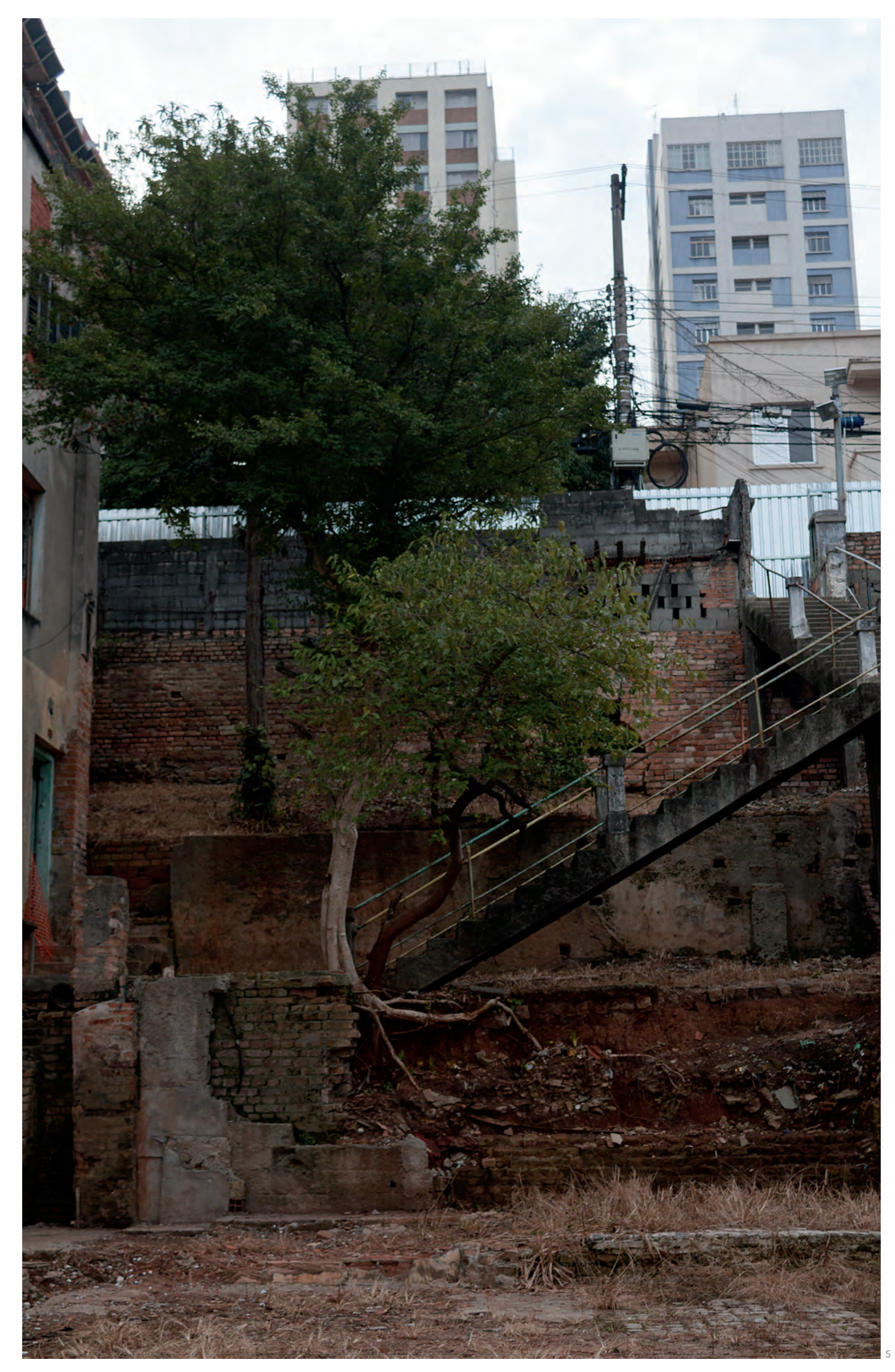

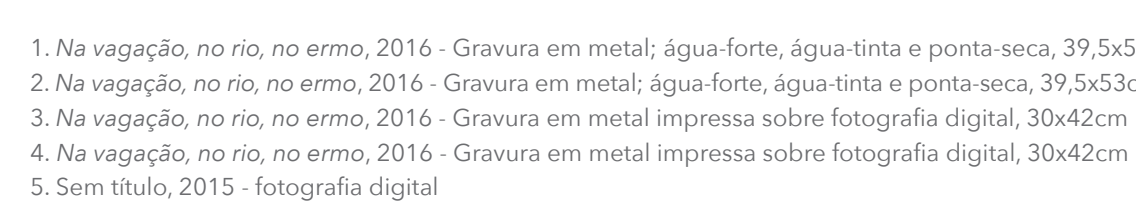


DESENHO

O desenho se faz presente como um meio fundamental, praticado em folhas avulsas agilidade e presteza sor .

Desenho em cadersos em formato de códex sanfon ou folder os quais proporcionam leituras distintas do formato, da sequência das páginas e da forma

Desenho figuras da açōes de justaposição e sobreposição. Me dit e exterior da forma, em sua est

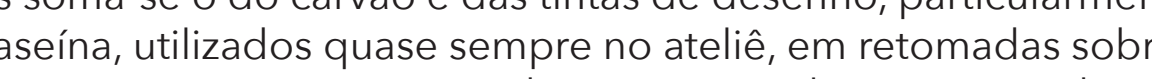

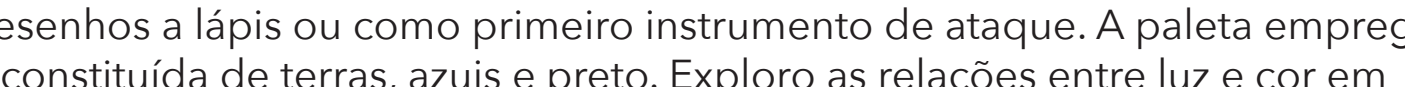

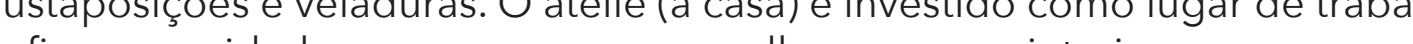

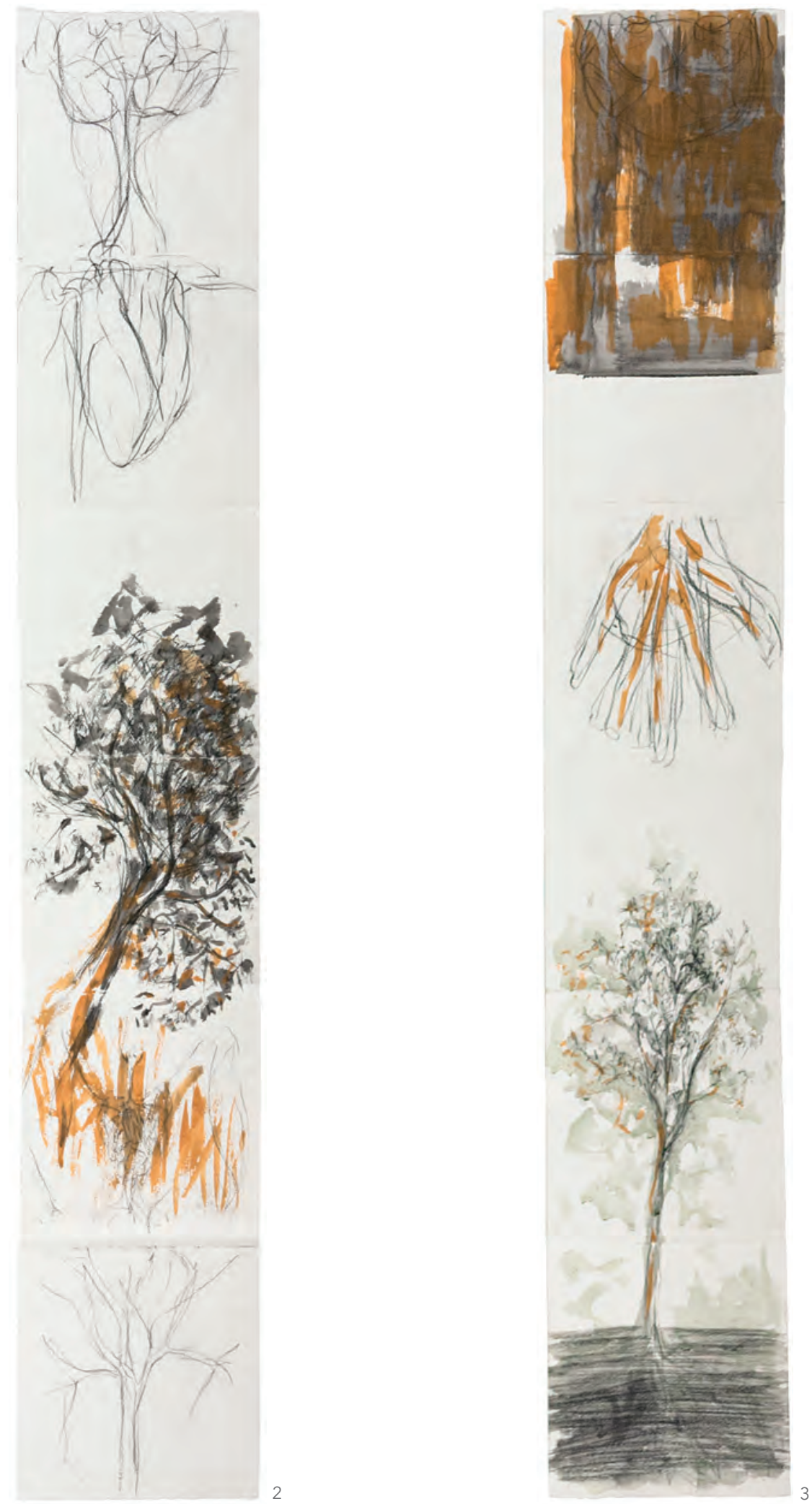

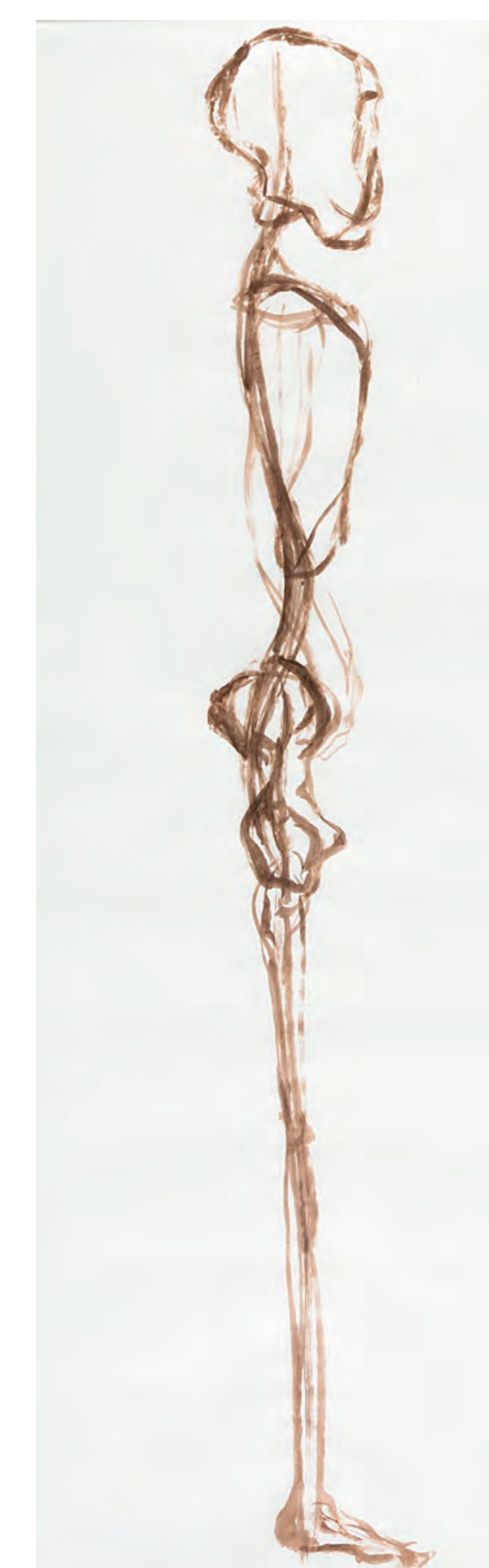

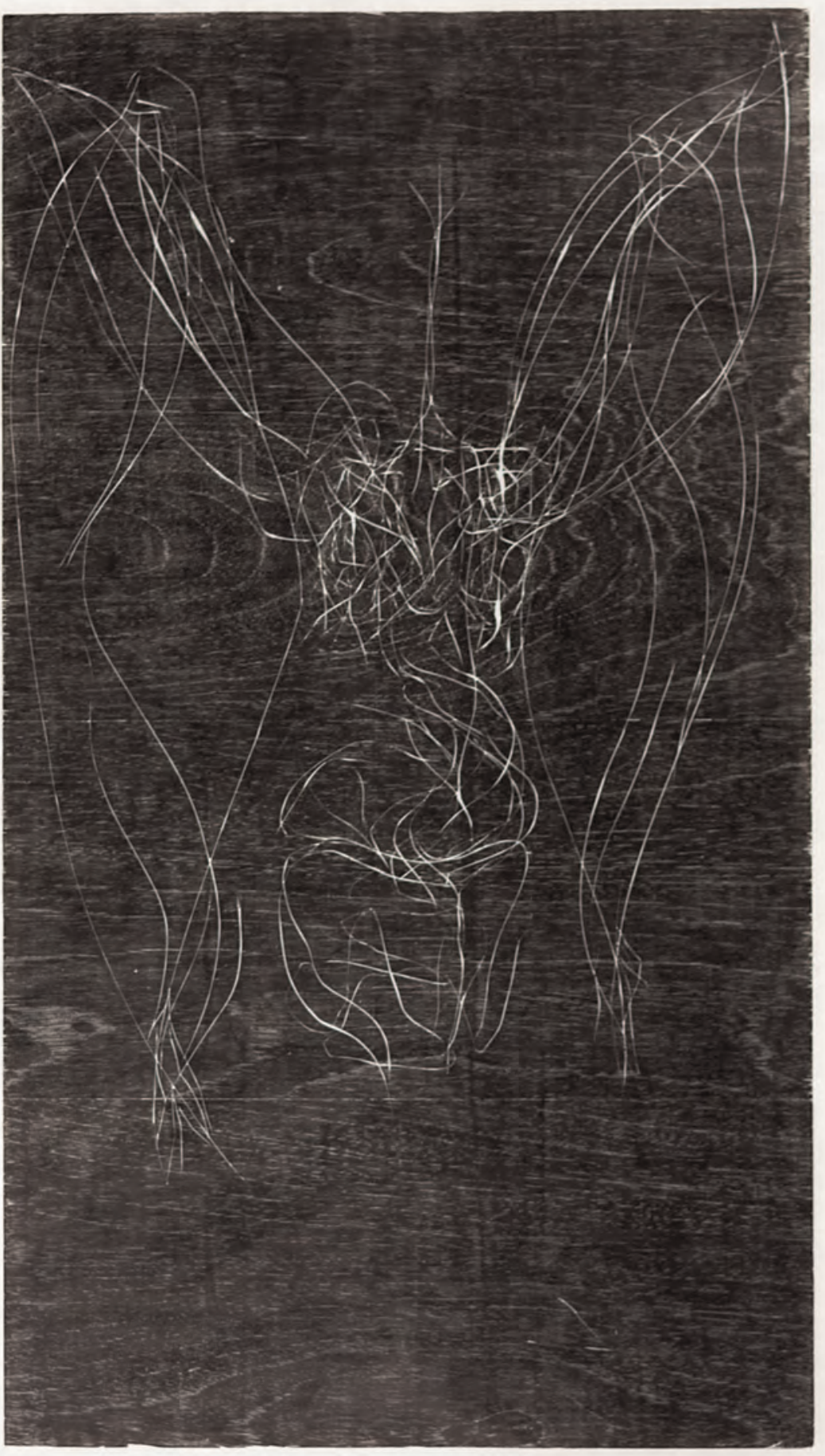

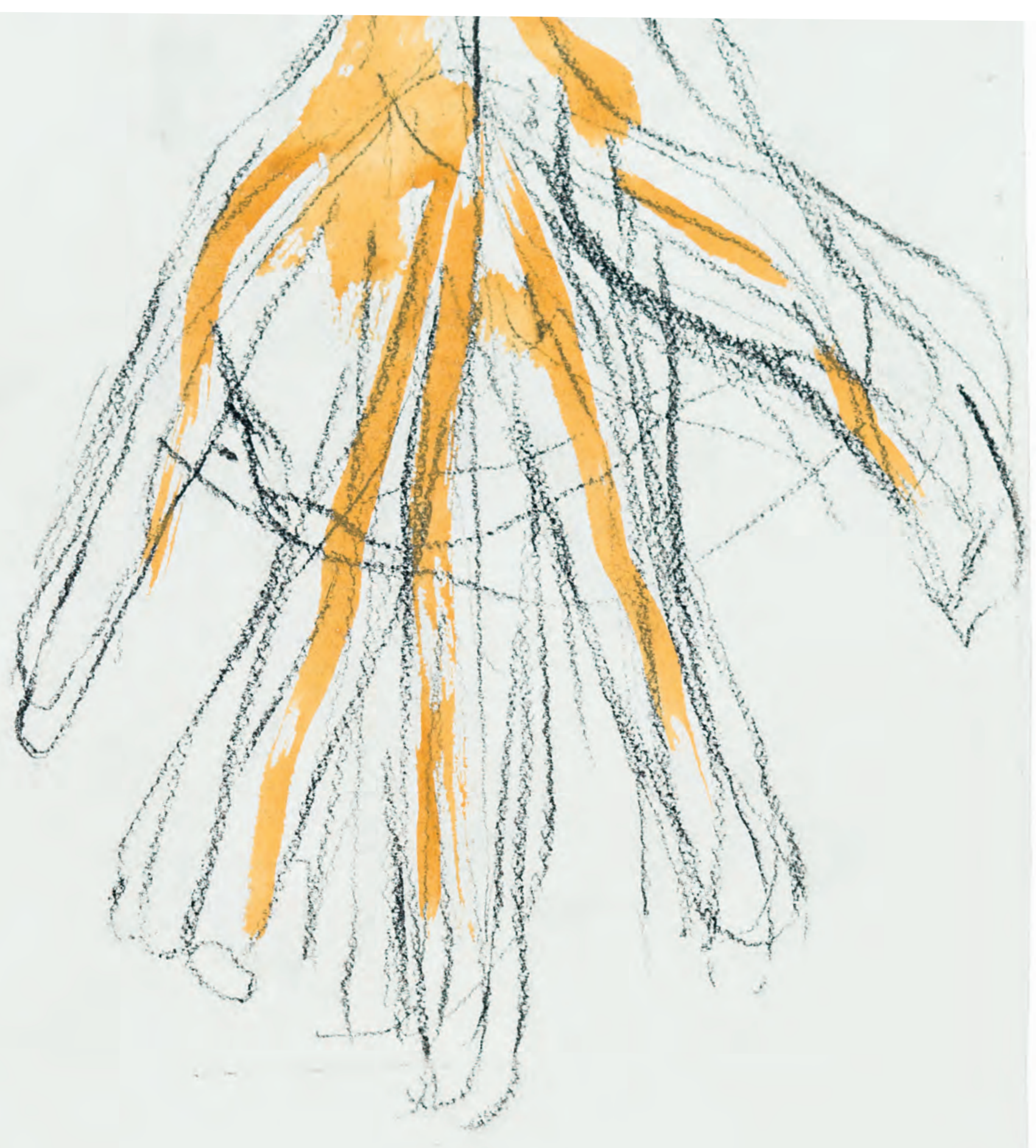

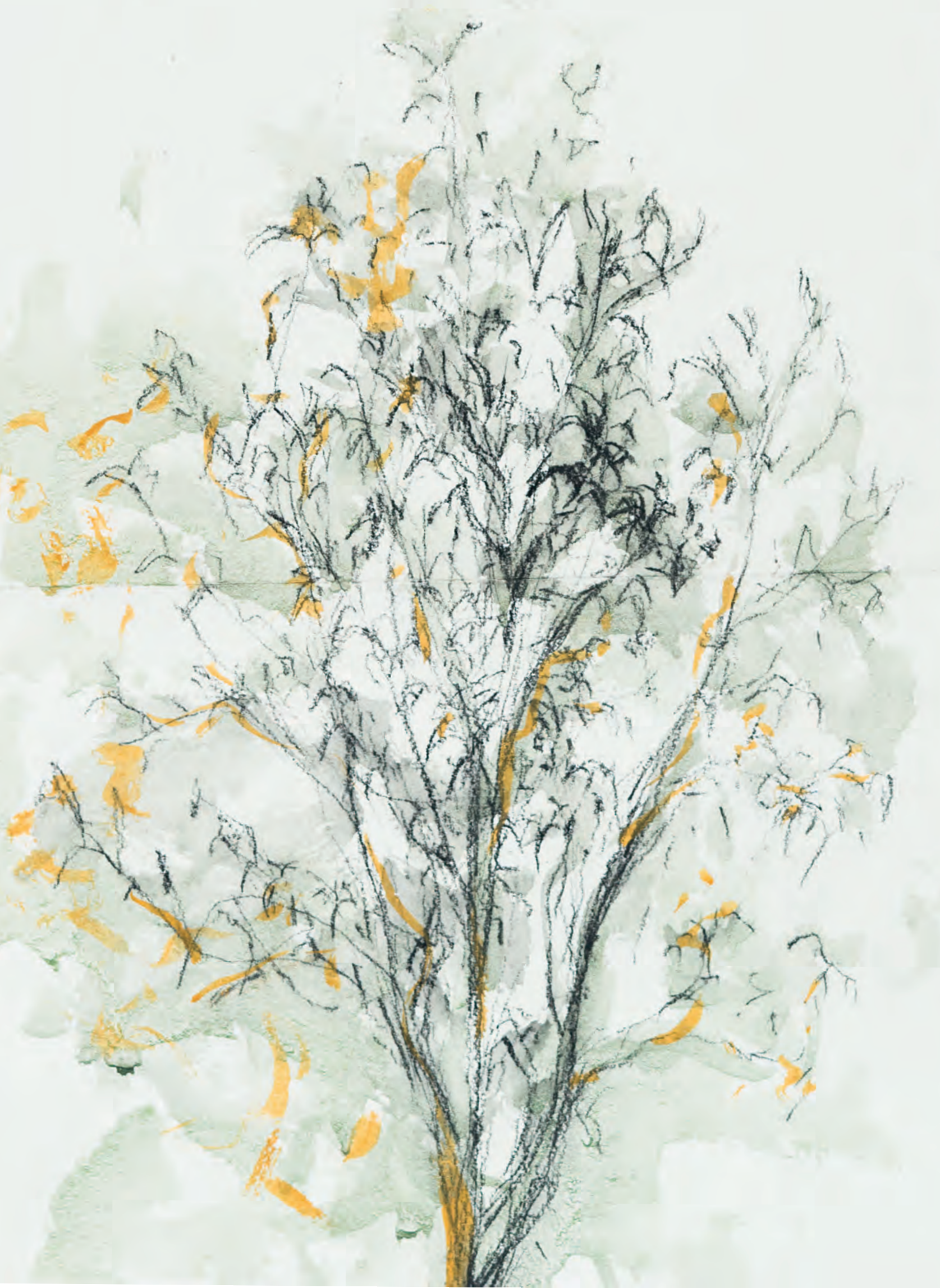



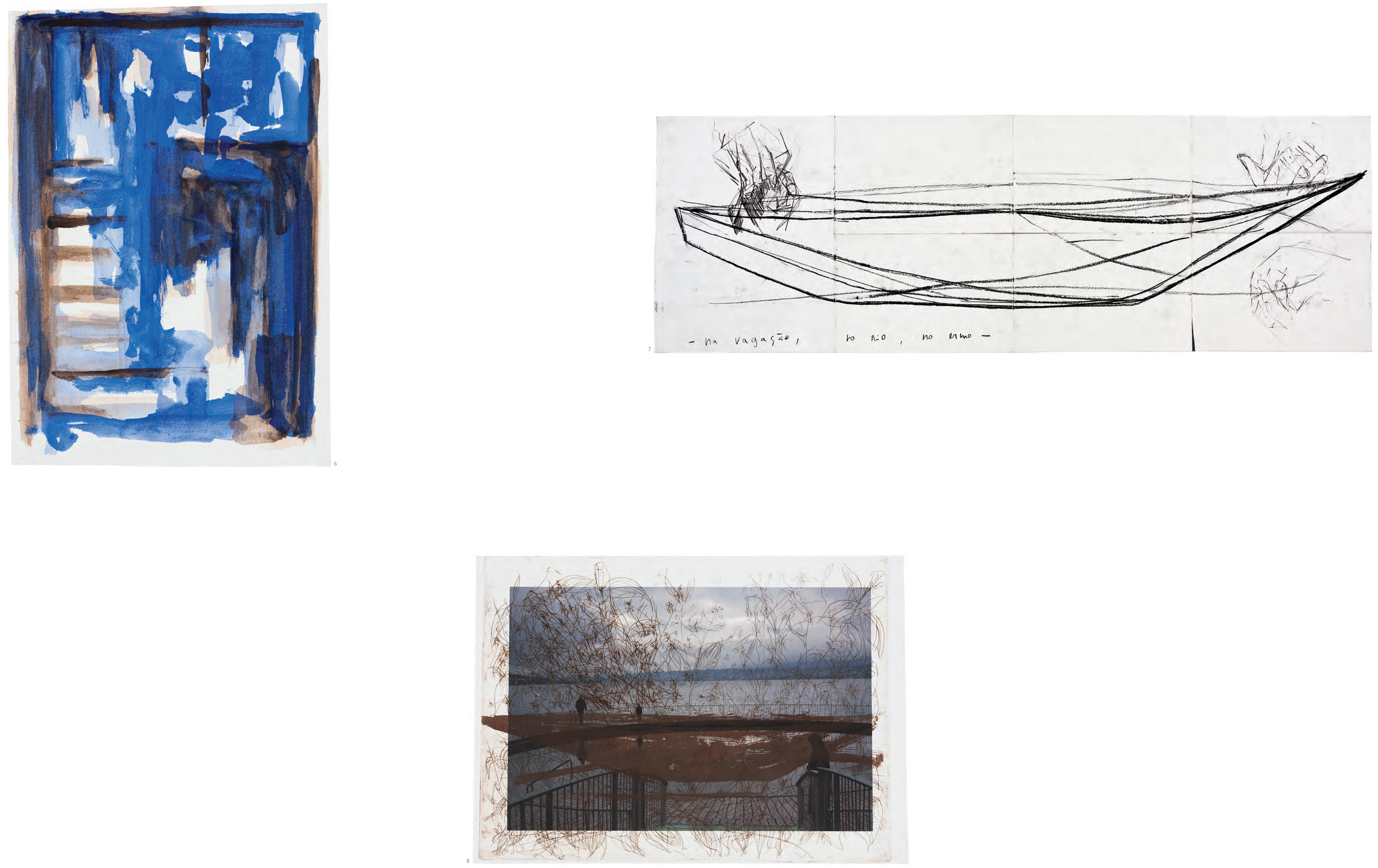

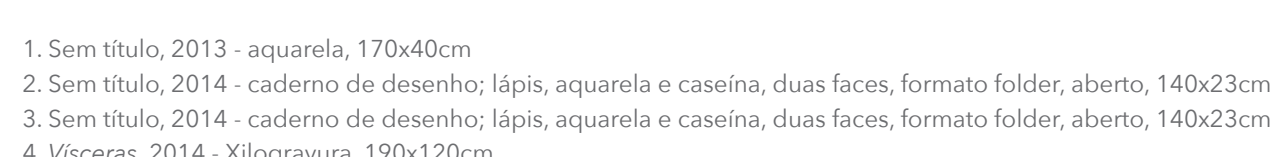


Caminho pela cidade que desenho, gravo e fotografo, e acompanha-me um
sonho recorrente. Nele encontro nos limites da cidade rios que se cruzam em águas por vezes cristalinas ou turvas. Em suas margens, edificaçōes se Ao percorrer a margem ou o interior do rio, deparo-me com o mar, que me

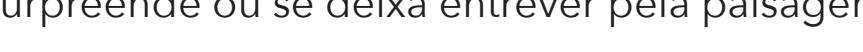

Cant

que irrompe e mutas vezes permanece oculta como seus rios. O devaneio abre espaço para a invençăa de figuras em que o visto e o sonh hado confluem

Os percursos e lugares fazem parte de um cotidiano e, assim, tornam-se obje associaç̄es com imagens do sonho e da memória, como a minha casa em elaçào a casa da infancia. O rio surge como uma figura constante, da lembran ao trabalho na cidade
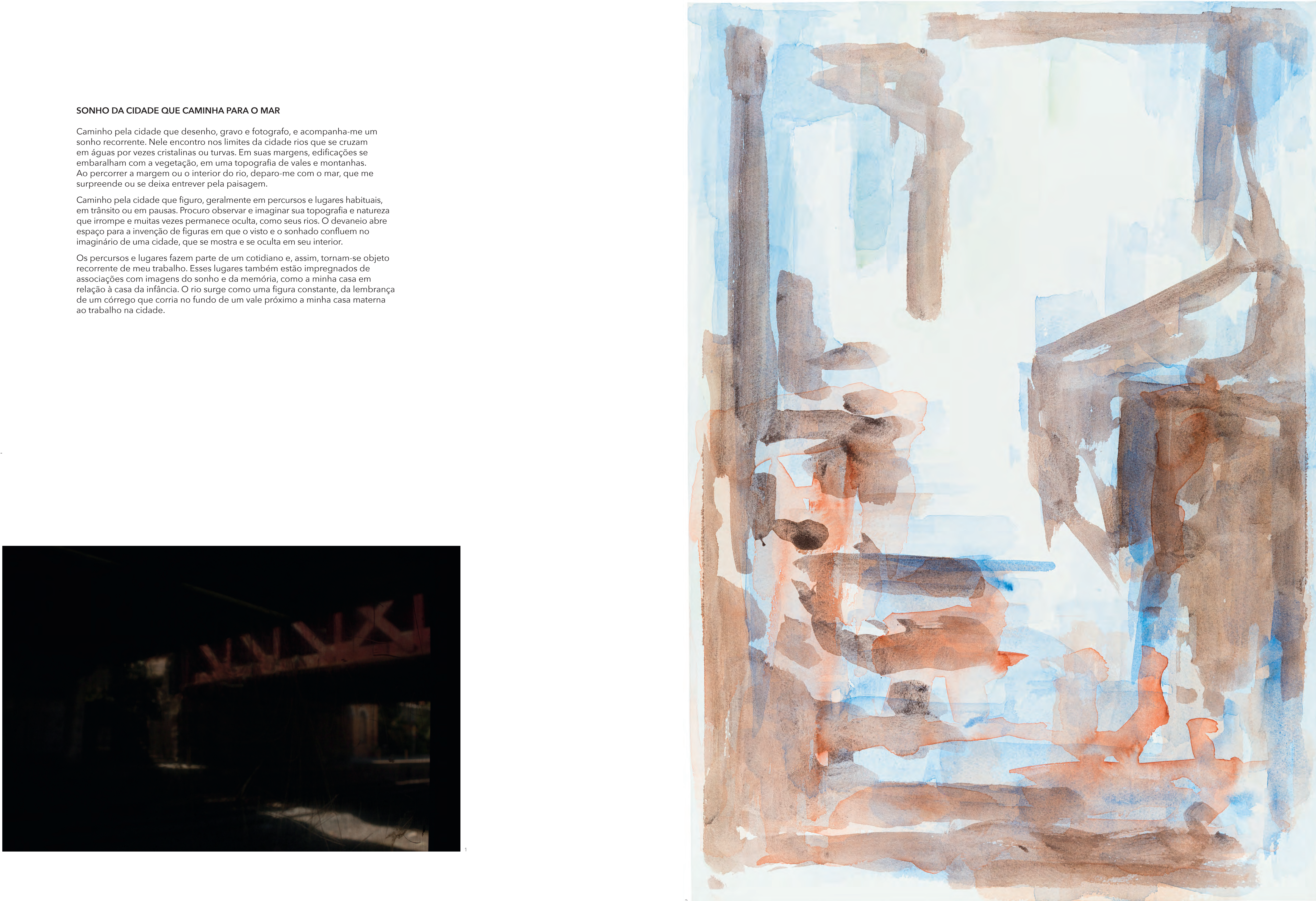

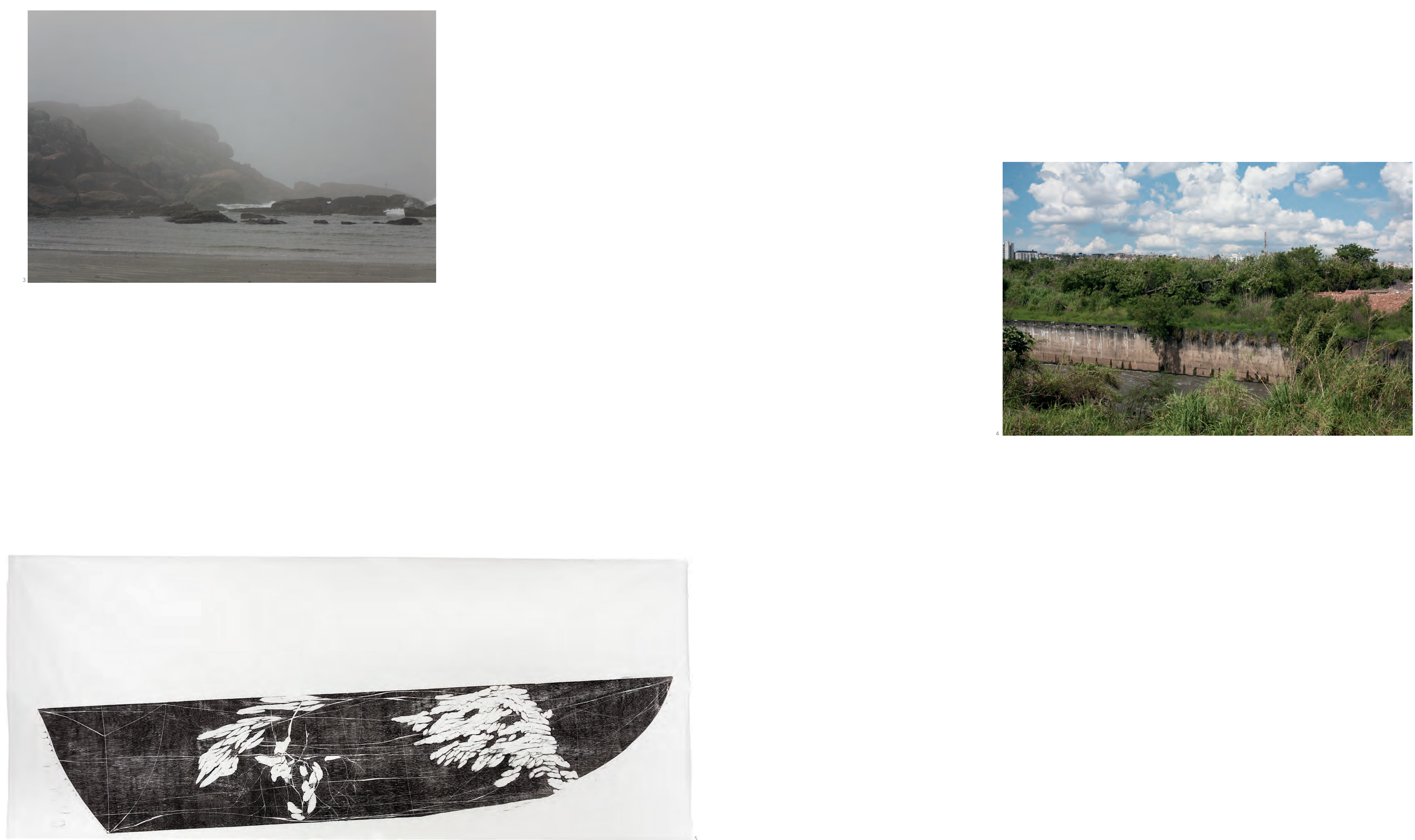

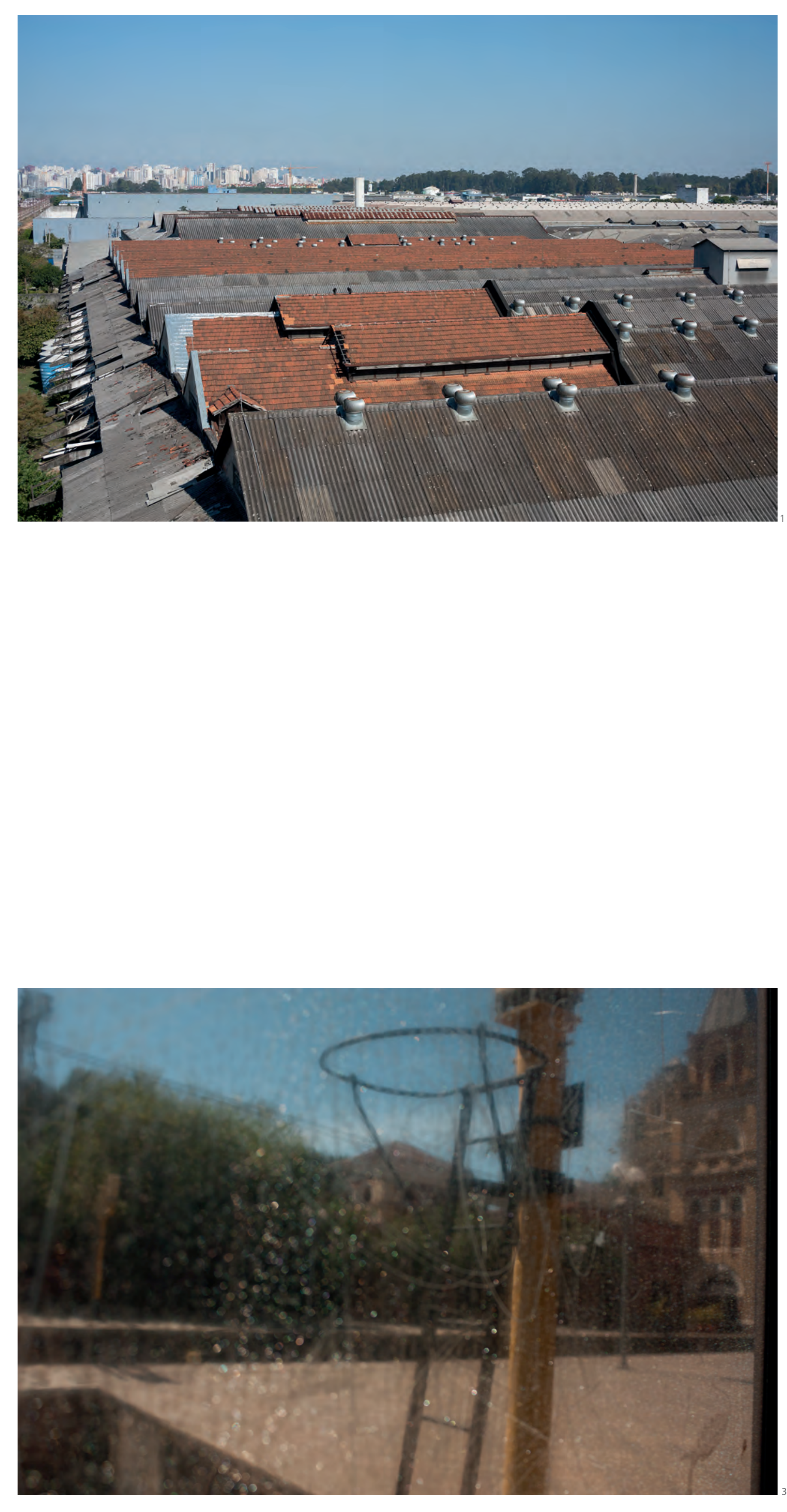

FOTOGRAFIA

Partindo das possibilidades de registro e documentaçâo, encontrei na fotografía um meio trabalho como o arquivo digitial, impressão e edição. Tendo como base a relação entre luz $e$
cor na construçăo da imagem, a fotografia se pôs em diálogo com o desenho e a gravura. Ao estudar os recursos de tratamento e impressão digital, revi as fotografias das colagens da fotografia enquanto construção, que se inaugura no instante do registro e destina-se à
im pressão. Nesse sentido, descobri potências em arquivos de fotoggrafias ja r realizadas, com - uso de ferramentas de tratamento de cor e luz, definidas em um espaço-cor estruturado em matiz, saturaçáa e luminosidade. Da mesma forma, a consciência desse processo mu tradução do arquivo em uma nova materialidade da imagem, considerando as diferenças se na densidade e intensidade da tinta depositada sobre o papel, em relação a seu campo. A edição, como escolha de imagens que se perfazem e se articulem, eque correspondan a a trabalho. Abre também espaço para o cotejmento entre fotografias, desenhos e gravuras o experimentaçoes misturando esses meios.

Arvore fotografadad, desenhada e gravada. Três figuraçōes distintas e que dialogam, na
singularidade de cada figura e nas especificicidades de cada meio. Na consideração sobre shich
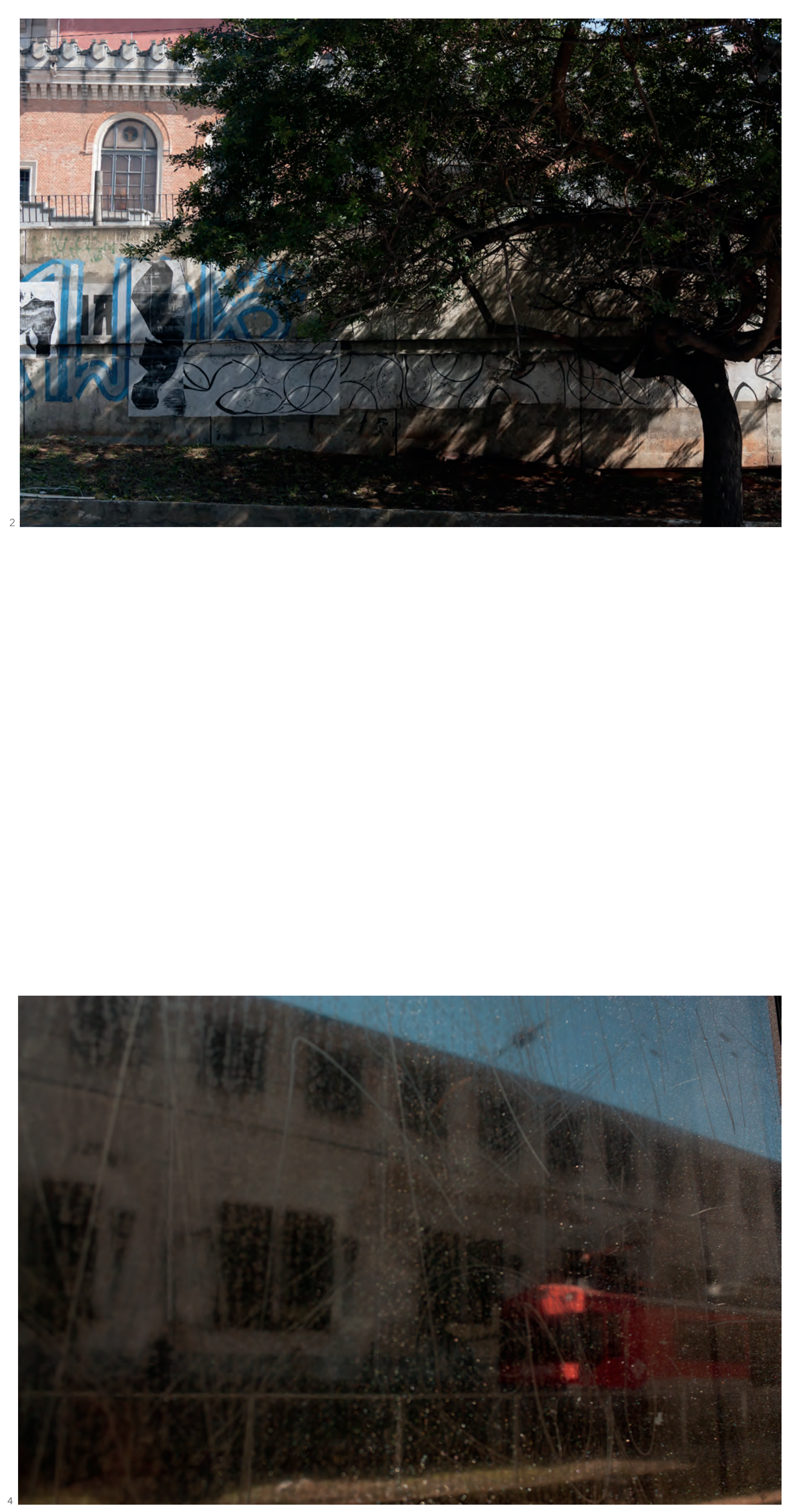

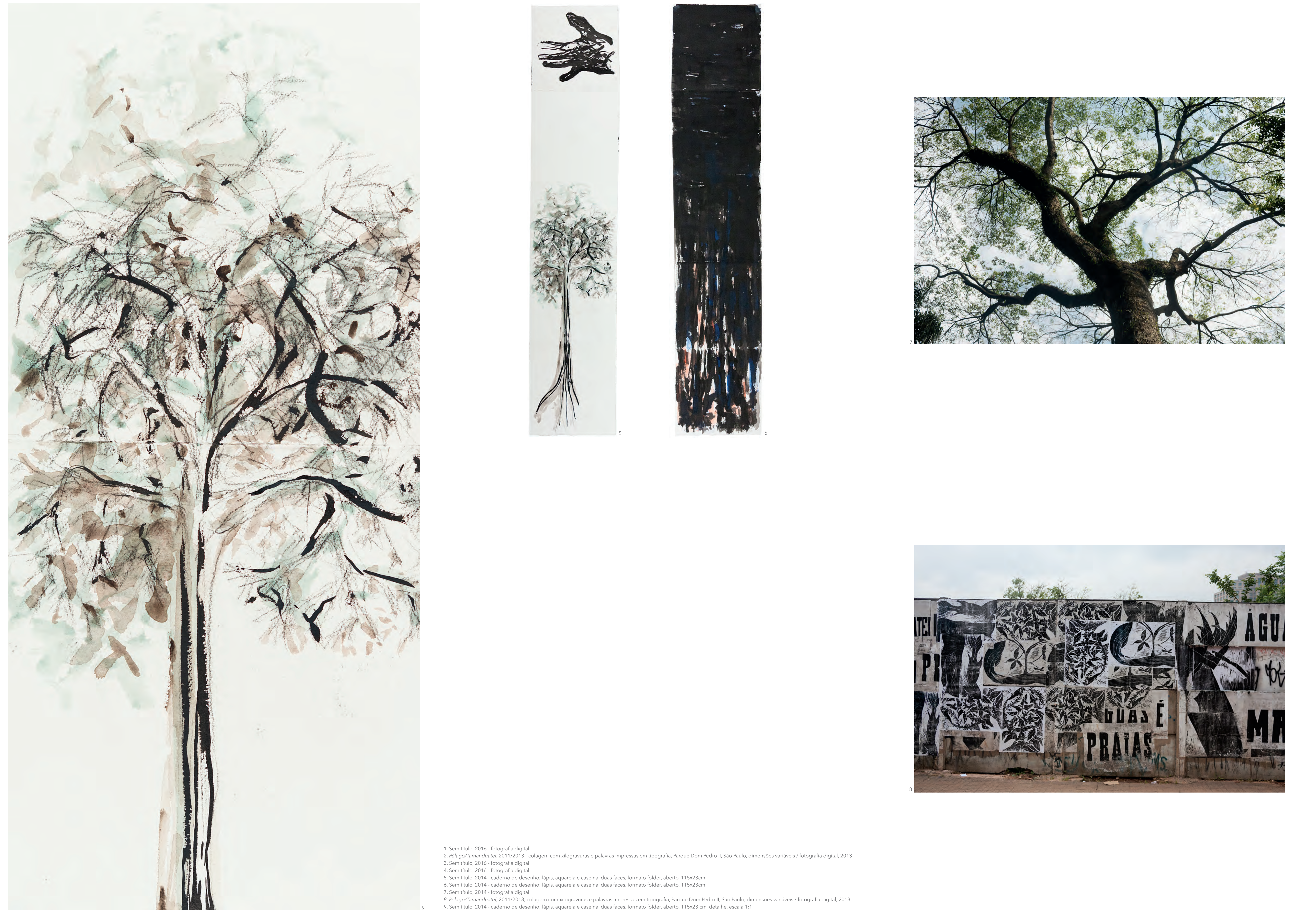

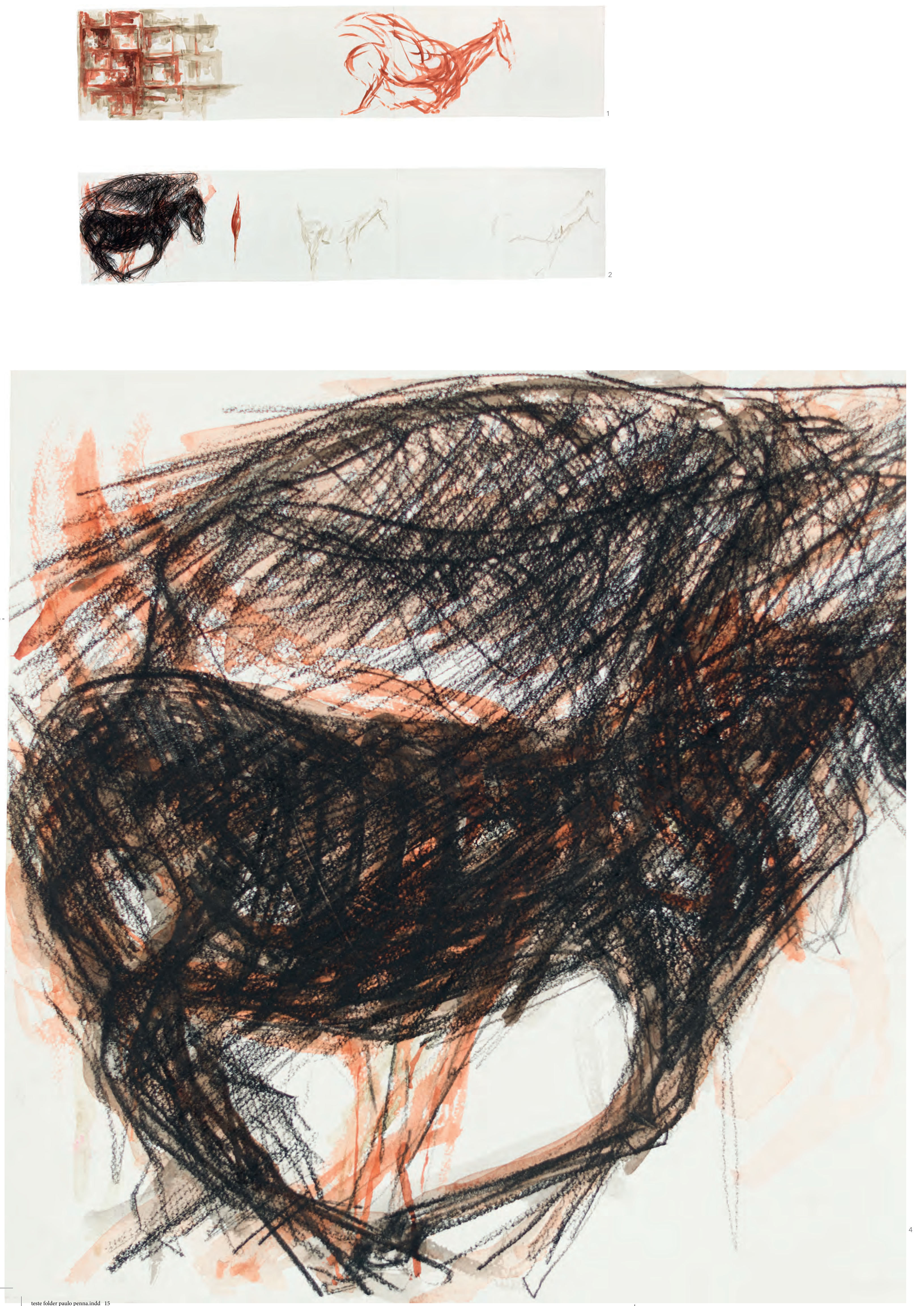

UM SER QUE CAMINHA PELA CIDADE
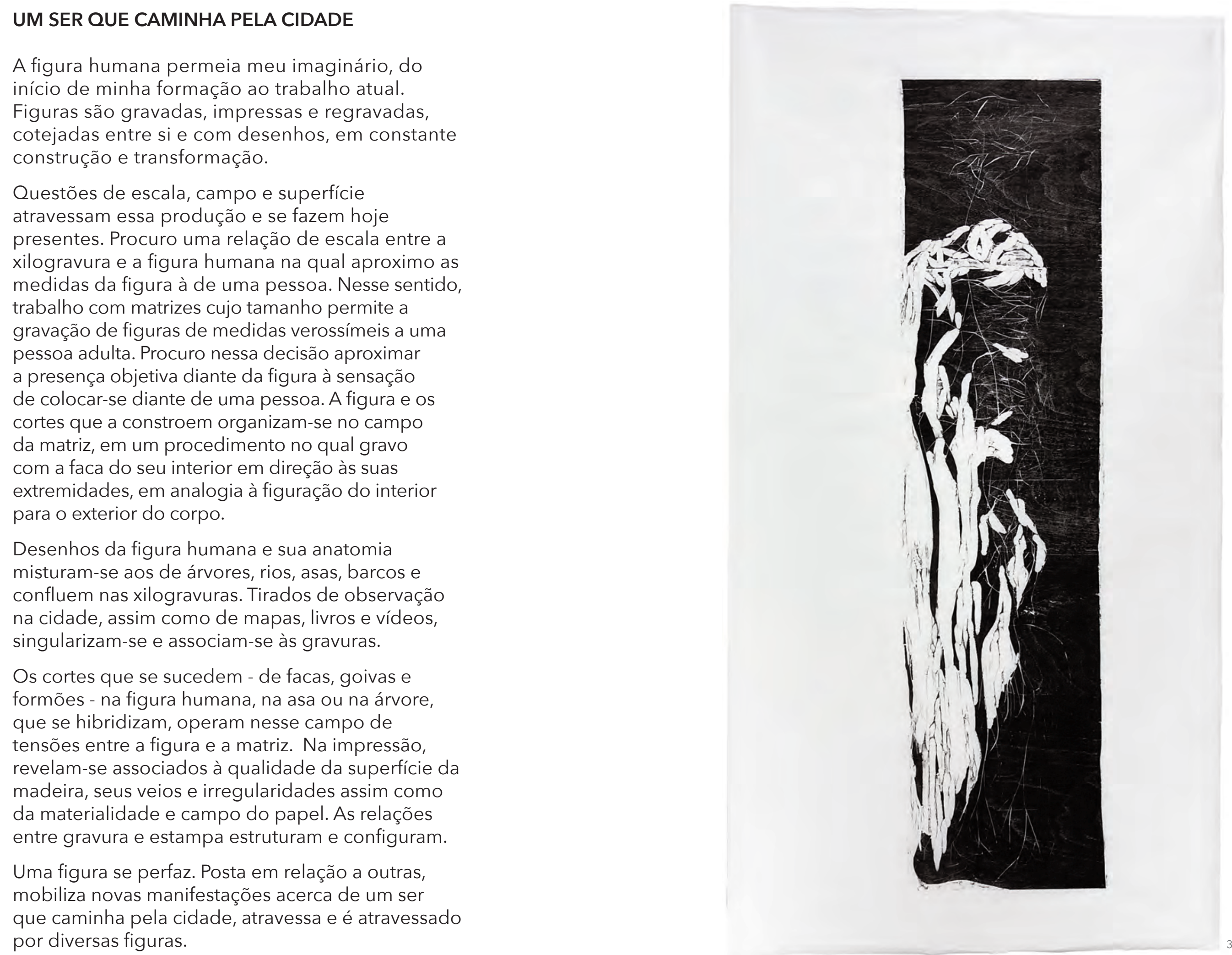

pordies

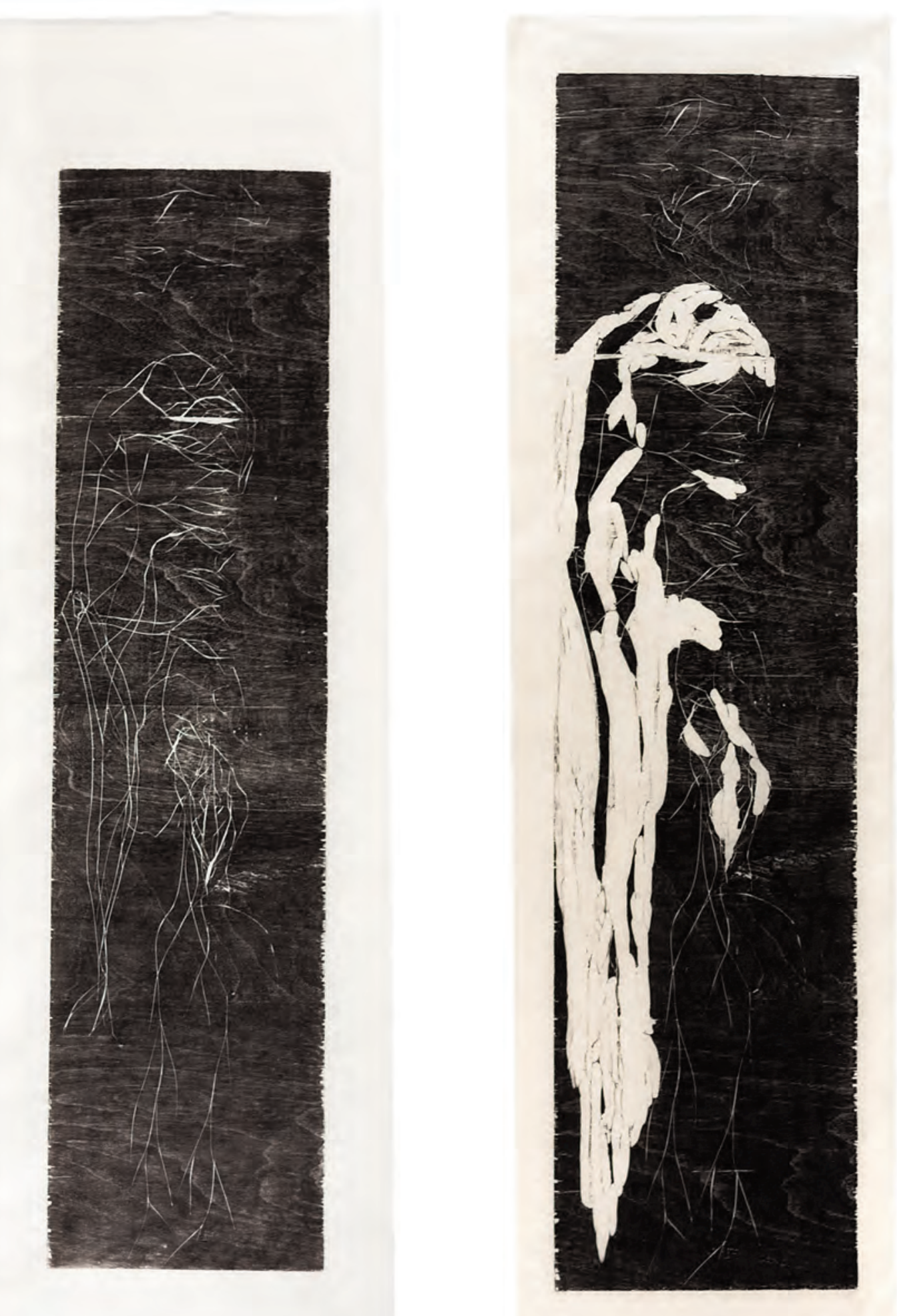



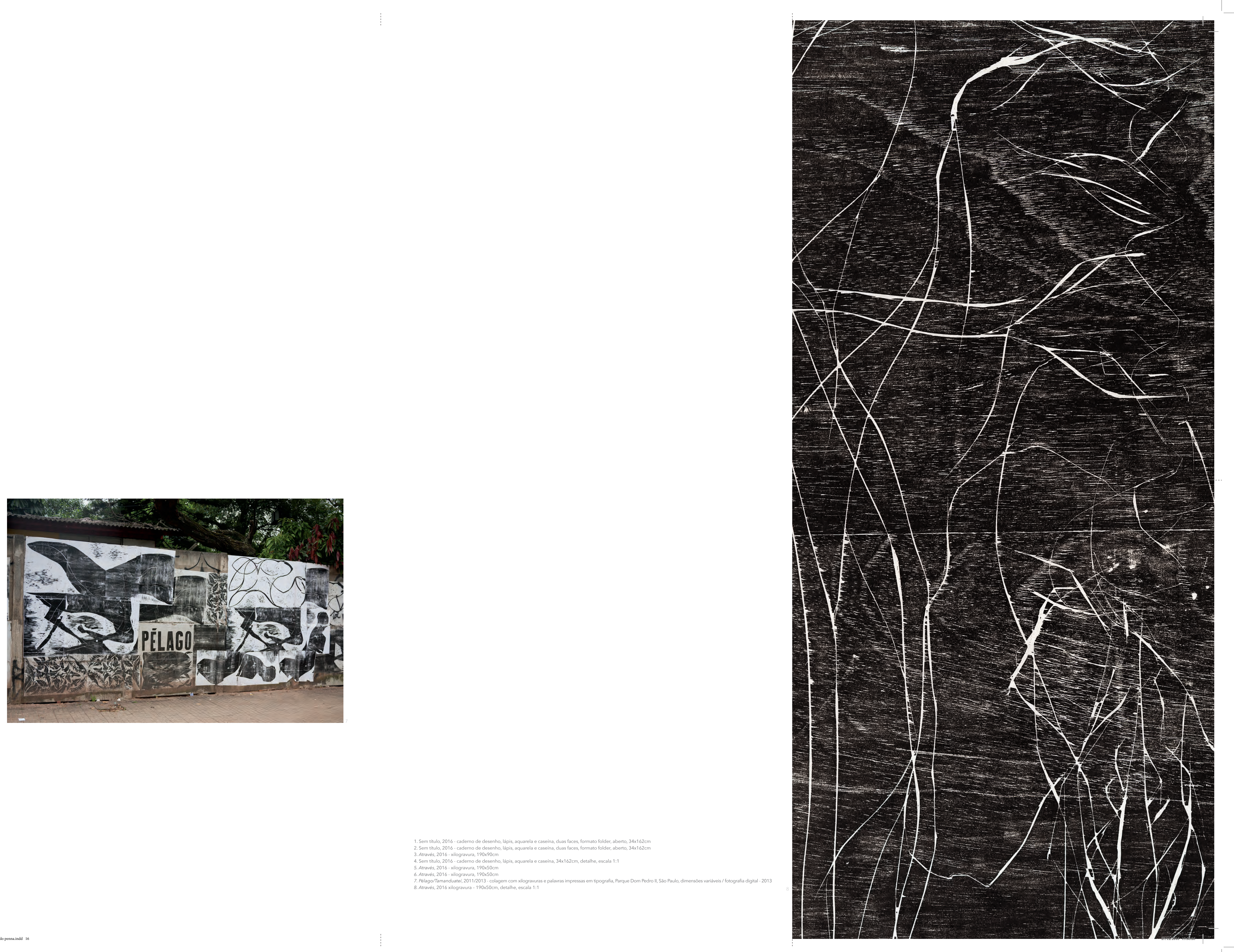



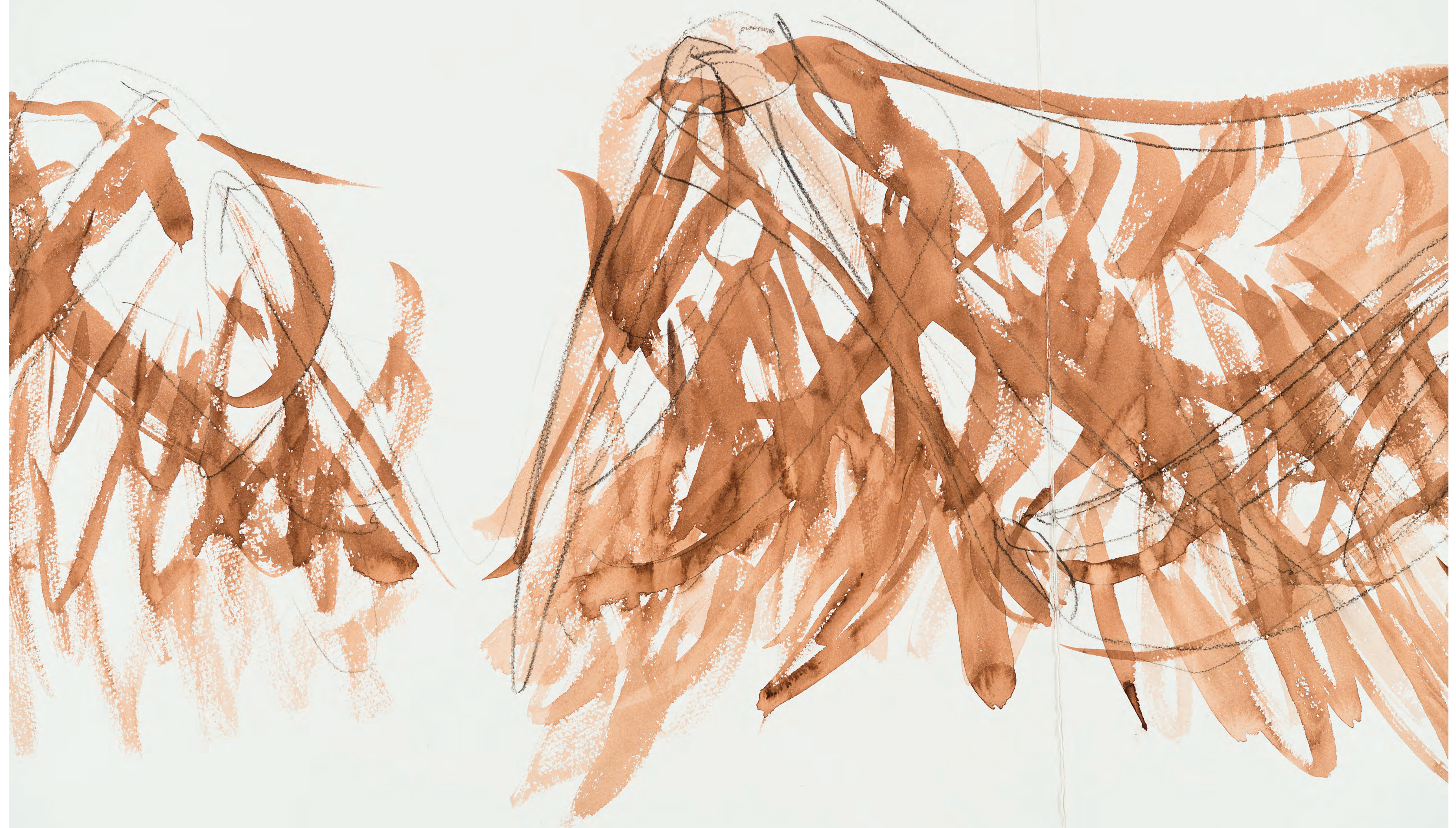

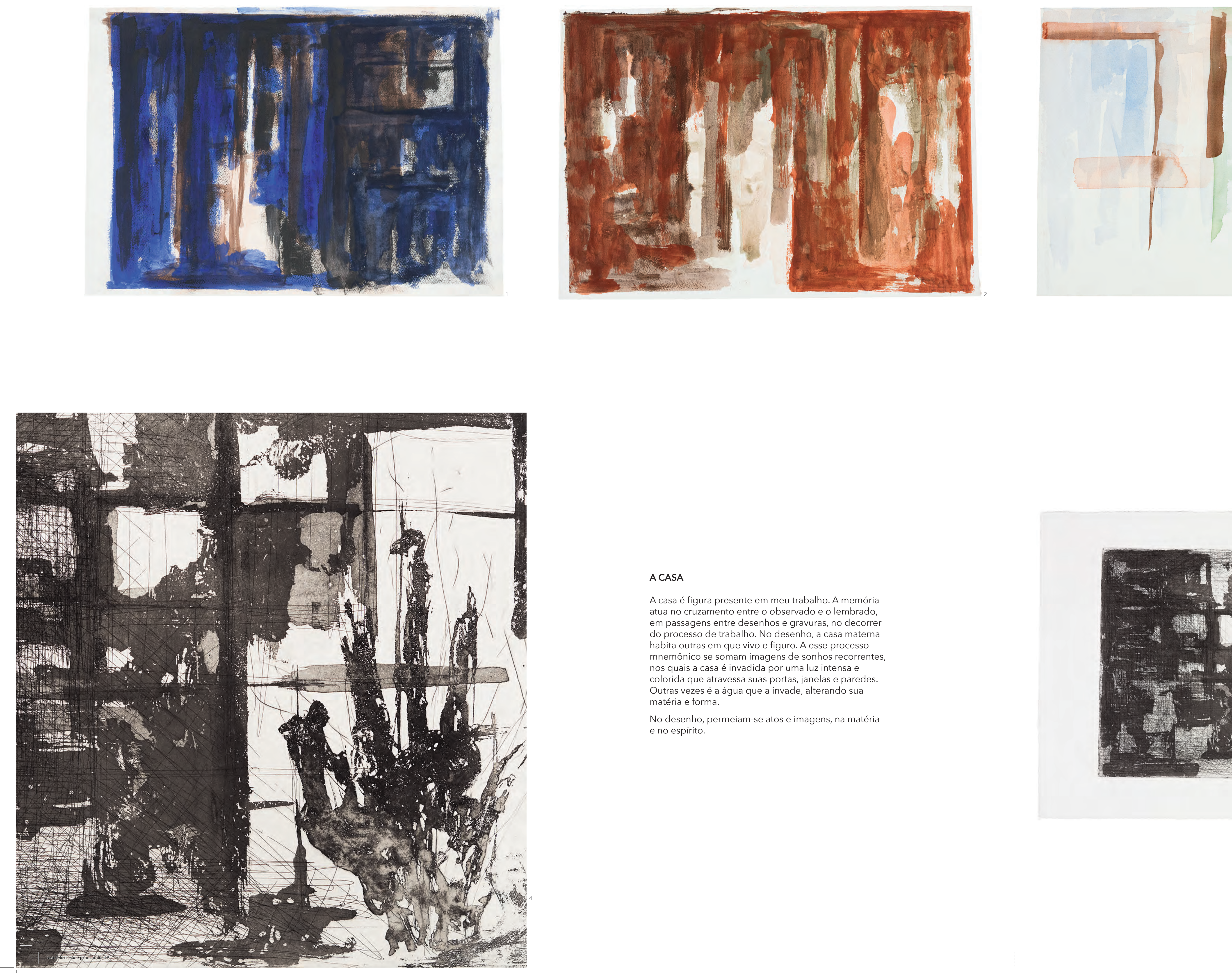

A CASA

A casa é figura presente em meu trabalho. A memória

em passagens entre desenhos e gravuras, no decorrer
do processo de trabalho. No desenho, a casa materna

habita outras em que vivo e figuro. A esse processo

nos quais a casa e invadida por uma luz in ten
colorida que atravessa suas portas, janta matréria e forma.
ma que a invade, alterando sua

e no espirito.

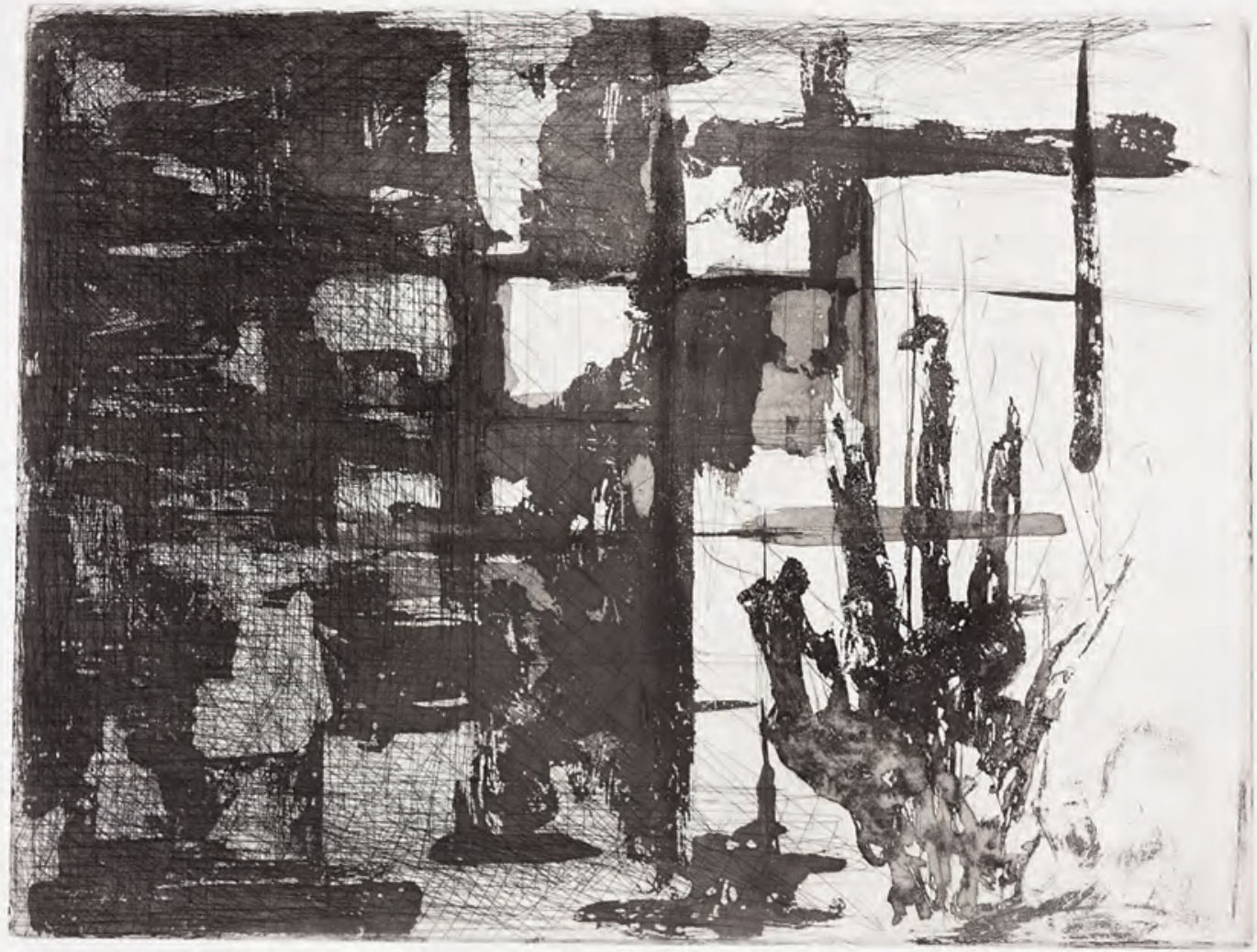








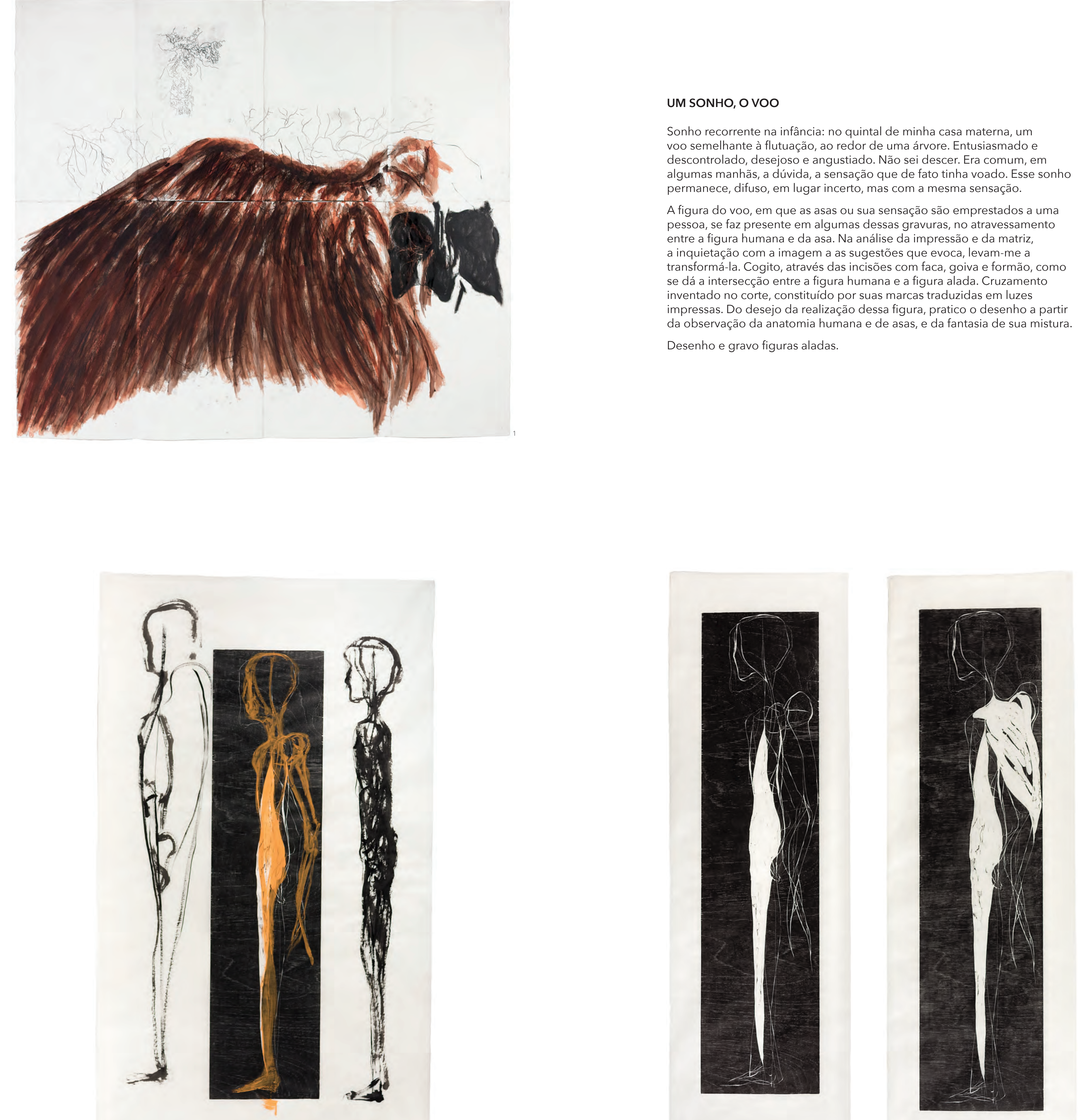

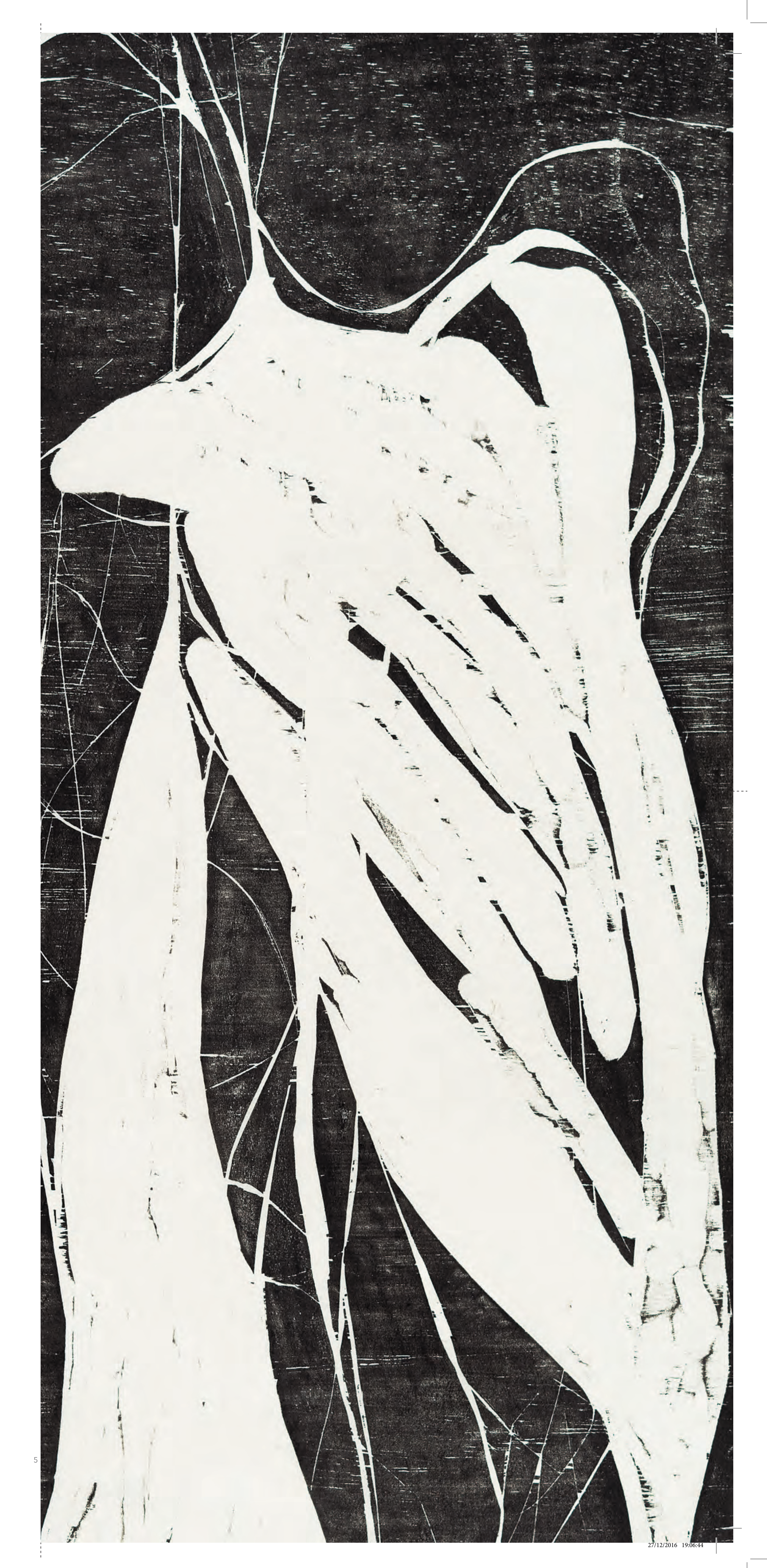



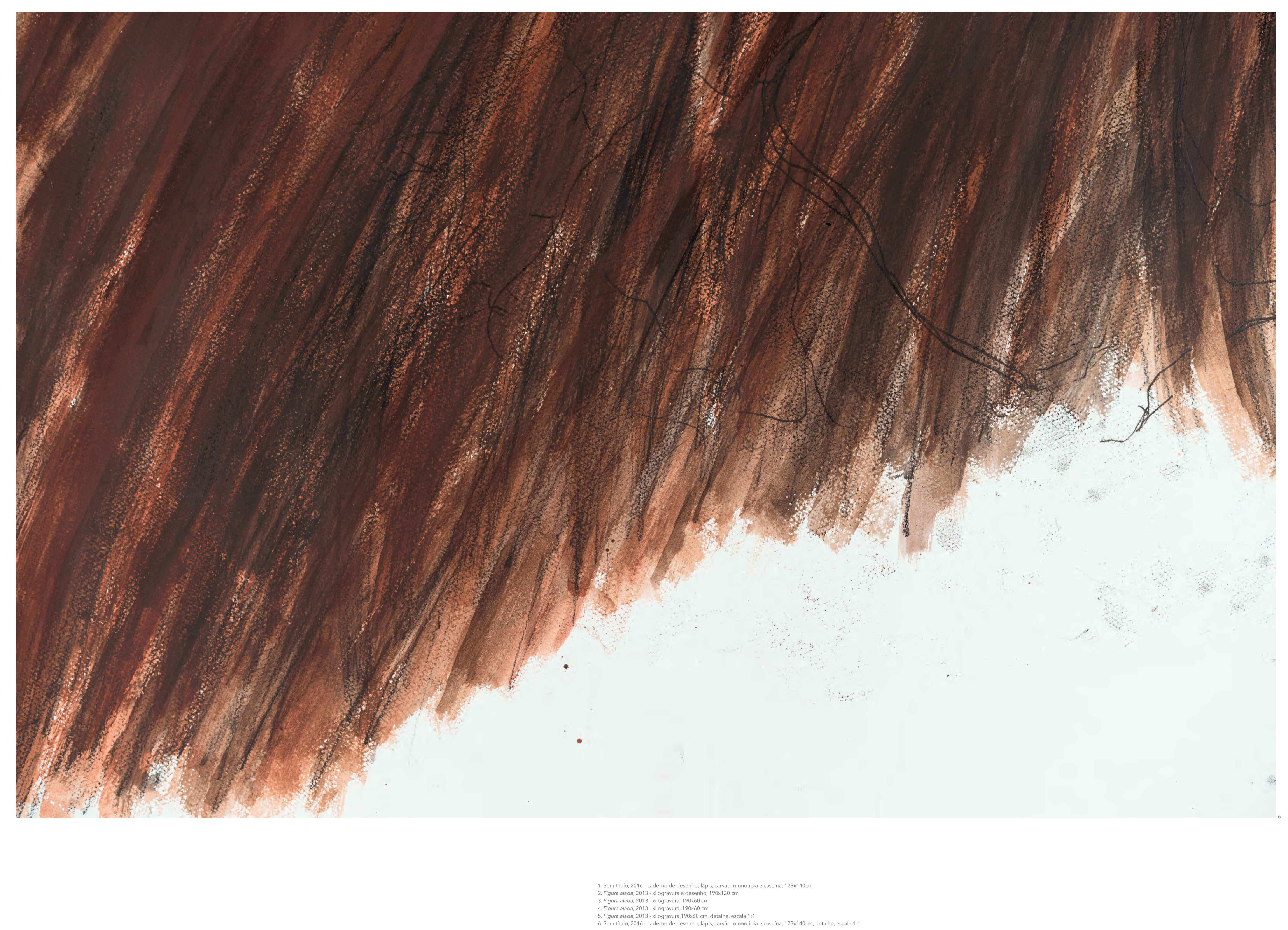

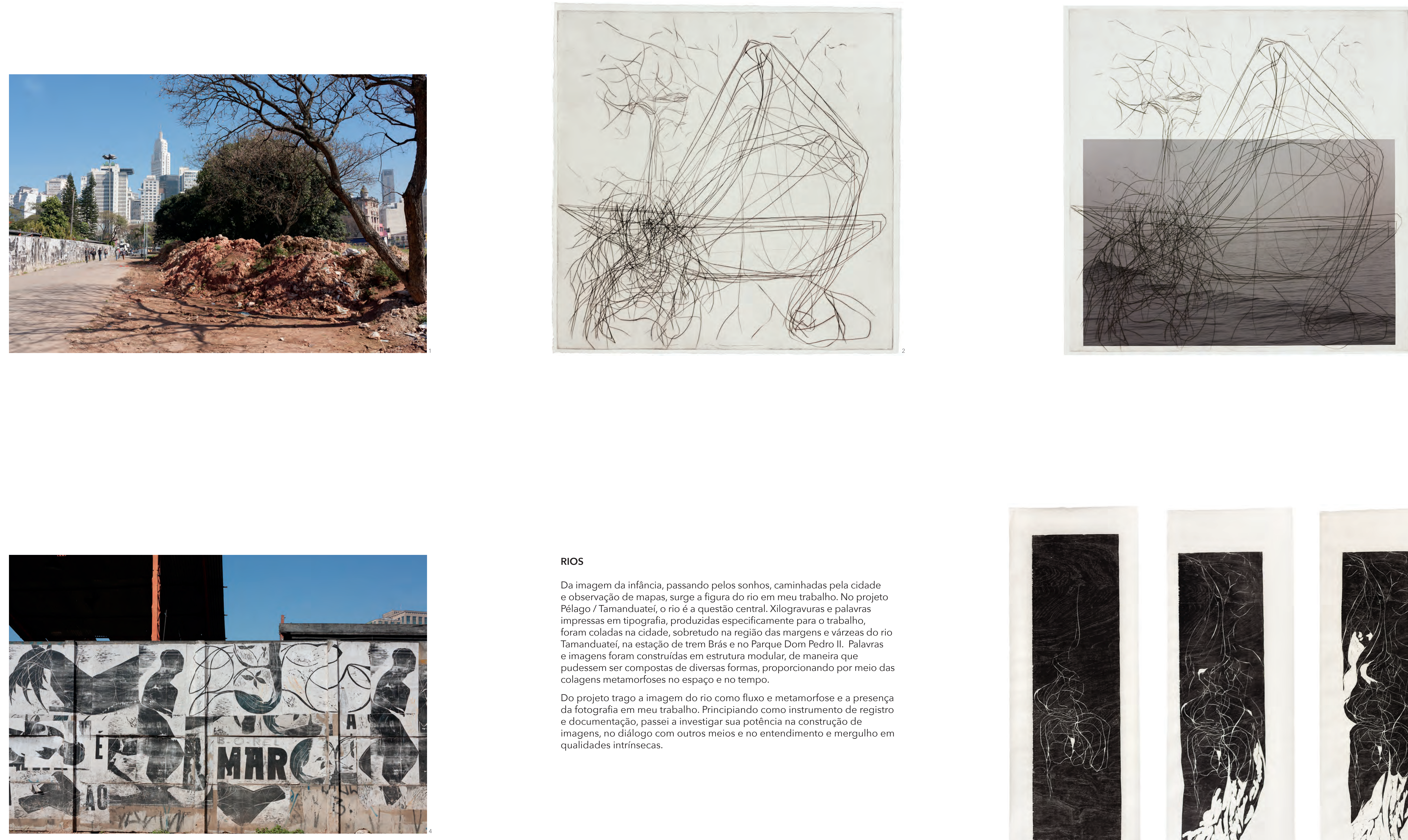

RIOS

Da imagem da infância, passando pelos sonhos, caminhadas pela cidade
e observacão de mapas, surge a figura do rio em meu trabalho. No projeto impressas em tipografia, produzidas especificamente para o trabalhos foram coladas na cidade, sobretudo na regláo das margens e varzeas do rio e imagens foram construídas em estrutura modular, de maneira que colagens metamortoses no espaço e no tempo.

Do projeto trago a imagem do rio como fluxo e metamortose e a presença imagens, no diálogo com outros meios e no entendimento e mergul ho em
qualidades intrínsecas.
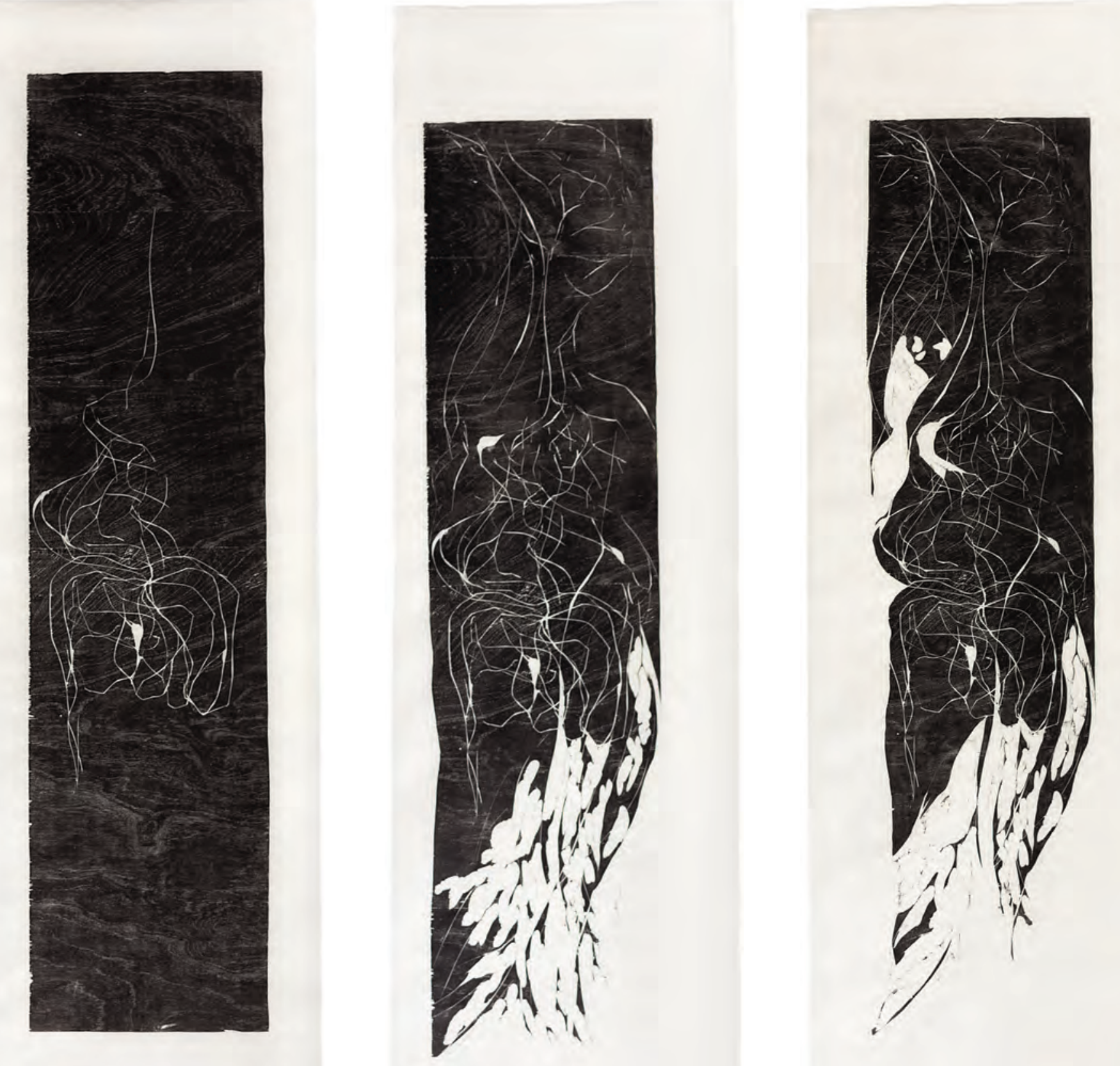

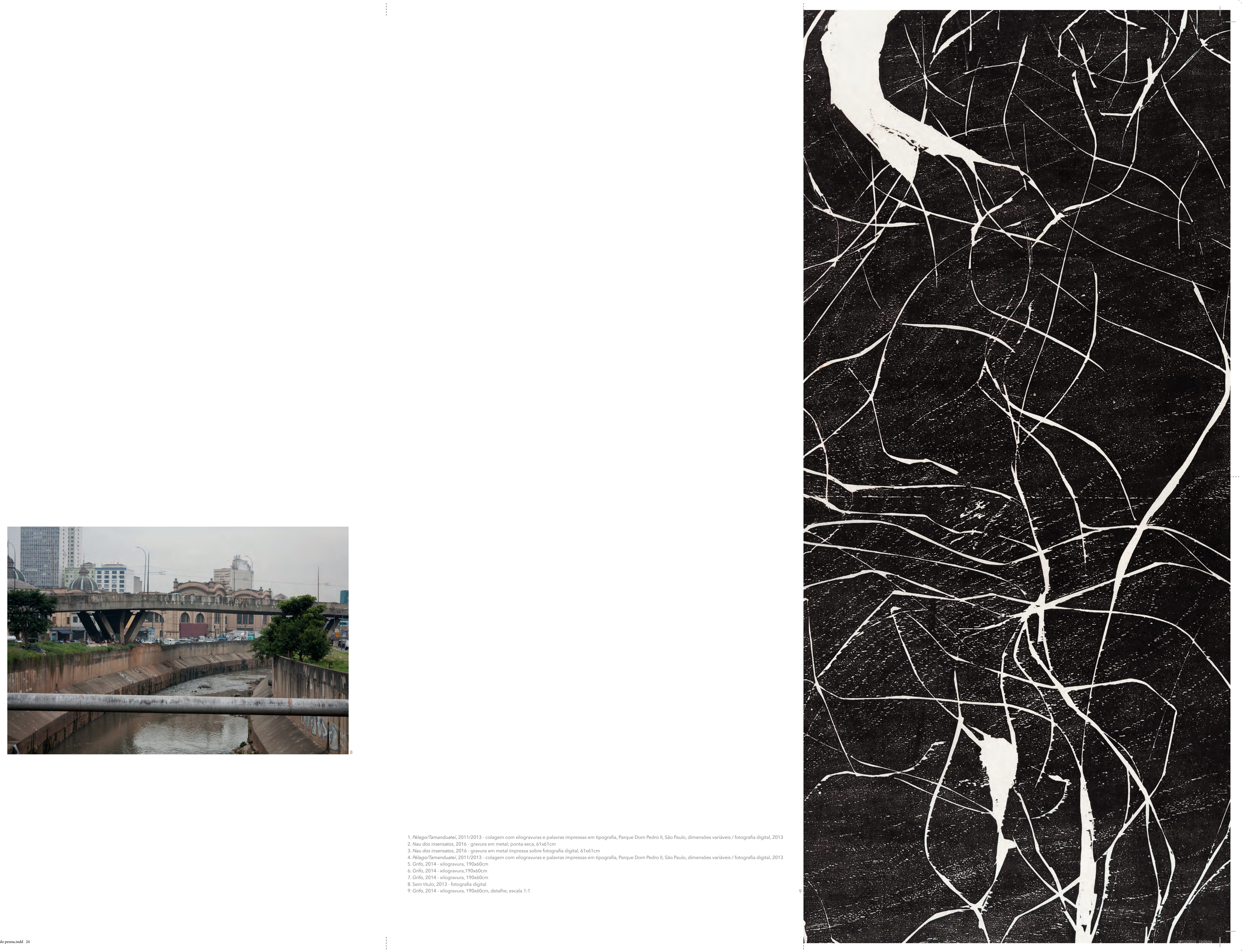
Paulo Camillo de Oliveira Penna

Desenho, fluxo, imagem

v. 1

São Paulo

2017 
Paulo Camillo de Oliveira Penna Desenho, fluxo, imagem

Tese Apresentada à Escola de Comunicações e Artes da Universidade de São Paulo para obtenção de título de Doutor em Artes

Programa: Artes Visuais

Área de Concentração: Poéticas Visuais

Orientador: Prof. Dr. Marco Francesco Buti

São Paulo, 2017 
Autorizo a reprodução e divulgação total ou parcial deste trabalho, por qualquer meio convencional ou eletrônico, para fins de estudo e pesquisa, desde que citada a fonte.

Catalogação na Publicação

Serviço de Biblioteca e Documentação

Escola de Comunicações e Artes da Universidade de São Paulo Dados fornecidos pelo (a) autor (a)

Penna, Paulo Camillo de Oliveira

Desenho, fluxo, imagem / Paulo Camillo de Oliveira

Penna. -- São Paulo: P. C. O. Penna, 2017.

2 v.: il.

Tese (Doutorado) - Programa de Pós-Graduação em Artes

Visuais - Escola de Comunicações e Artes / Universidade de São Paulo.

Orientador: Marco Francesco Buti

Bibliografia

1. Desenho 2. Gravura 3. Fotografia I. Buti, Marco

Francesco II. Título.

CDD 21.ed. - 760 
Paulo Camillo de Oliveira Penna

\section{Desenho, fluxo, imagem}

Tese Apresentada à Escola de Comunicações e Artes da Universidade de São Paulo para obtenção de título de Doutor em Artes

Programa: Artes Visuais

Área de Concentração: Poéticas Visuais

Orientador: Prof. Dr. Marco Francesco Buti

São Paulo, 2017

Banca Examinadora 


\section{RESUMO}

Apresento um conjunto de figuras - construídas através do desenho, fotografia e gravura- que movem um imaginário de seres e lugares, em trânsito entre o olhar, a memória e o sonho. A forma é proposta em sua materialidade e em correspondência a seus referentes. $O$ enfrentamento de questões técnicas e poéticas está presente necessariamente na realização de cada trabalho e no trânsito entre eles. Da necessidade de invenção das figuras operam o entendimento e as ações em sua construção. O estudo e experimentação dos meios empregados no trabalho constituem-se nesse escopo. Proponho que toda manifestação se singularize e abra-se ao cotejamento, no tempo, entre diversas manifestações. Nesse sentido, permeiam-se as figuras, os meios construtivos e seu imaginário. Imaginar e figurar como sentimento e ação em si e no mundo.

Palavras-chave: Desenho; Gravura; Fotografia; Figura; Cor; Luz; Forma. 


\begin{abstract}
I present a body of artwork - build through drawing, photography and printmaking that move an imagery of beings and places in transit between the perception, the memory and the dream. The form is proposed in its materiality and in correlation to its referents. The confrontation between technical and poetic matters is necessarily present in the making of each work and the movement among them. It is from the need for the invention of each piece of work that the understanding and the actions through the construction work. The study and experimentation with the media applied in the process are within the scope of this work. I propose that each manifestation is singled out and then cross analyzed, in time, with the other manifestations. This way each work permeates imagination and media. Imagining and figuring as feeling and action in itself and the world.
\end{abstract}

Key-words: Drawing; Printmaking; Photography; Figure; Color; Light; Form. 


\section{BIBLIOGRAFIA}

ALAIN MICHAUD, Philippe (org.). Comme le Rêve le Dessin, Dessins Italiens des XVle et XVIle siécles du Musée du Louvre, Dessins Contemporains du Centre Pompidou. Editions du Centre Pompidou/Éditions du Louvre, Paris, 2005.

ALBERTI, Leon Batista. Da Pintura. Campinas, Ed. Unicamp, 1999.

ANDRADE, Mario de. O Turista Aprendiz. Belo Horizonte, Itatiaia, 2002.

ARISTÓTELES. Arte Poética. in A Poética Clássica/Aristóteles, Horácio, Longino. Introdução por Roberto de Oliveira Brandão ; tradução direta do grego e do latim por Jaime Bruna. São Paulo, Cultrix 2005.

BARTHES, Roland. A Câmara Clara. Rio de Janeiro, Ed Nova Fronteira, 1984. Trad. Júlio Castañon Guimarães.

BAXANDALL, Michael. O Olhar Renascente, Pintura e Experiência Social na Itália da Renascença. Rio de Janeiro, Paz e Terra, 1991.

BENJAMIN, Walter. A obra de arte na era de sua reprodutibilidade técnica, in Obras escolhidas. São Paulo, Brasiliense, 1986.

BERGSON, Henri. Matéria e Memória - Ensaio sobre a relação do corpo com o espírito. São Paulo, Martins Fontes 2006.

BLUNT, Anthony. Teoria Artística na Itália 1450 - 1600. São Paulo. Cosac e Naify Ed. 2001. 
BLUM, André. Les Primitifs de la Gravure sur Bois, Étude Historique et Catalogue des Incunabules Xylographiques du Musée du Louvre. Paris: Librarie Grundi, 1956

BUTI, Marco, LETYCIA, Anna (orgs). Gravura em Metal. São Paulo, Edusp: Imprensa Oficial do Estado, 2002.

BRANT, Sebastian. A Nau dos Insensatos. São Paulo, Ed. Octavo, 2010.

CAREY, Francis and GRIFFITHIS, Antony. The Print in Germany 1880-1933. The Age of Expressionism. The Trustees of the Britsh Museum, 1993.

CARREIRA, Eduardo. (organização, tradução e comentários). Estudos de Iconografia Medieval: O Caderno de Vuillard de Honnecourt, arquiteto do século XIII. Brasília, Editora Universidade de Brasília, 1997.

CASTLEMANN, Riva. Prints of the XX Century (revised and enlarged edition). Londres: Thames and Hudson, 1988.

CENNINNI, Cenninno. Il libro dell'Arte o Tratatto della Pittura. Milano, Lognesi, 1975.

CENTRO CULTURAL SÃO PAULO. Lívio Abramo, Xilogravuras. KATZ, Renina Pedreira (org.). São Paulo, Centro Cultural São Paulo, Imprensa Oficial do Estado, 1983.

FILÓSTRATO, o Velho. Amores e Outras Imagens. São Paulo, Hedra, Coleção Bienal, 2012.

FLORMANN, Lisa Carol. Myths and Methamorphosis: Picassos classical prints of the 1930s. Massachussets Institute of Chicago, 2000.

FOUCAULT, Michel. Stultifera Navis. Em: FOUCAULT, Michel. História da Loucura na Idade Clássica. São Paulo: Perspectiva, 2014.

GHIRRI, Luigi. Pensar Por Imagens. Ícones, Paisagens, Arquiteturas. São Paulo, Instituto Moreira Salles, 2013.

GHIRSHMAN, Roman. Iran, Partians and Sassanians. Thames and Hudson, 1962.

HESÍODO. Trabalhos e Dias. Organização e tradução. Christian Werner. São Paulo, Hedra, 2013. 
Teogonia. Estudos e tradução, Jaa Torrano. São Paulo, lluminuras, 1991.

HIND, Arthur M. XV A History of Engraving and Etching; from the Century to the year 1914. New York, Dover Publications Inc. 1963.

An Introduction to the History of the Woodcut. New York: Dover Publications Inc. 2 vol.

HORÁClO, Arte Poética. Em: A Poética Clássica/Aristóteles, Horácio, Longino. Introdução por Roberto de Oliveira Brandão; tradução direta do grego e do latim por Jaime Bruna. São Paulo, Cultrix, 2005.

IVINS Jr. W.M. Imagem Impressa y Conocimiento; analisis de la imagem pre fotografica. Barcelona, Gustavo Gilli, 1975.

KANDINSKY, Wassily; MARC, Franz. Almanaque O Cavaleiro Azul / Editado por Wassily Kandinsky, Franz Marc; organização, Jorge Schwartz. São Paulo, Editora da Universidade de São Paulo; Museu Lasar Segall, Ibram - Minc, 2013.

KOSSOVITCH, Leon; LAUDANNA, Mayra e RESENDE, Ricardo. Gravura Brasileira. São Paulo, Cosac e Naify / Itaú Cultural, 2000.

KOSSOVITCH, Leon; LAUDANNA, Mayra. Marcello Grassmann 1942-1955. São Paulo, Editora da Universidade de São Paulo, 2013.

KRAUSS, Rosalind. O Fotográfico. Barcelona, Editorial Gustavo Gilli, 2002. Trad. Anne Marie Davée.

LICHTENSTEIN, Jacqueline (org.). A pintura - Vol.9: O desenho e a cor. organização de Jacqueline Lichtenstein; coordenação da tradução de Magnólia Costa. São Paulo: Ed 34, 2006.

A pintura - Vol.4: O belo. organização de Jacqueline Lichtenstein; coordenação da tradução de Magnólia Costa. São Paulo: Ed 34, 2004.

MERLEAU-PONTY, Maurice. Fenomenologia da Percepção. São Paulo, Martins Fontes, 1999.

MOROVIC, Jan. Color Gamut Mapping. Nova Jersey, John Wyley and sons Ltd, 2008. 
MUSEU DE ARTE BRASILEIRA - FAAP. Goeldi seu tempo, Goeldi nosso tempo. RIBEIRO, M. Isabel; BATISTA, Marta Rosseti (org). São Paulo, Museu de Arte Brasileira/ FAAP, 1995.

OVÍDIO. Metamorfoses. Tradução e Notas, Bocage. São Paulo, Hedra, 2007.

PANOFSKY, Erwin. Renascimento e Renascimentos na Arte Ocidental. Lisboa, Presença, 1981.

PARSHALL, Peter; SELL, Stacey; BRODIE, Judith. The unfinished print. Washington, National Gallery of Art in association with Lund Humphries, 2001.

PARSHALL, Peter; LANDAU, David. The renaissance print 1470-1550. New Haven and London, Yale University Press, 1994.

PARSHALL, Peter e SCHOCH, Rainer, com AREFORD, David S.; FIELD, Richard S.; SCHMIDT, Peter. Origins of European Printmaking: fifteenth century woodcuts and their public. Washington, National Gallery of Art, in association with Yale University Press, New Haven and London, 2005.

PASSOS, Maria Lúcia Perrone; EMÍDIO, Teresa. Desenhando São Paulo, Mapas e Literatura, 1877-1954. São Paulo, Imprensa Oficial, 2009.

PÉREZ-ORAMAS, Luis. An Atlas of Drawings. The Museum of Modern Art, New York, 2006.

PINACOTECA DO ESTADO DE SÃO PAULO. O desenho estampado, a obra gráfica de Evandro Carlos Jardim MUBARAC, Cláudio (curadoria e organização). São Paulo, Pinacoteca do Estado de São Paulo, 2005.

PINACOTECA DO ESTADO DE SÃO PAULO. Giacometti. WIESINGER, Véronique (org.). São Paulo, Cosac Naify, 2012.

PLíNIO, o Velho. Histoire Naturelle. Paris, Les Belles Lettres, 1985.

PON, Lisa. Raphael, Durer e Marcantonio Raimondi - Copying and the Italian Renaissance Print. Yale Press University, New Haven and London, 2004.

PUENTES, Fernando Rey. A Téchne em Aristóteles. Em: Hypnos número 4, Téchne. Centro de Estudos da Antiguidade Grega. Departamento de Filosofia da PUC-SP. São Paulo.

EDUC. Palas Athena, 1998. 
RIBEIRO, Noemi Silva. Oswaldo Goeldi: um auto retrato. Rio de Janeiro: Centro Cultural do Banco do Brasil, 1995.

ROSA, Guimarães. A terceira margem do rio. In: ROSA, Guimarães, Primeiras Estorias. São Paulo, Ed. Nova Fronteira 2001.

RUFINONI, Priscila Rossinetti. Oswaldo Goeldi: iluminação, ilustração. São Paulo, Cosac Naify e Fapesp, 2006.

SALZSTEIN, Sônia (org.). No Vazio do Mundo - Mira Schendel. São Paulo, Marca D'Água, 2006.

SLIVE, Seymour. The drawings of Rembrandt, A New Study. London, Thames and Hudson, 2009.

STAROBINSKI, Jean. Peut-on définir l'essai?, in BONNET, Jacques (org.). Jean Starobinski. Paris, Centre Georges Pompidou, 1985.

TOLEDO, Benedito Lima de. São Paulo: Três Cidades em um Século. São Paulo, Duas Cidades, 1983.

UNIVERSIDADE DE CAMPINAS. ELUF, Marcello Grassmann, Coleção Cadernos de Desenho. Lygia (org). Campinas, Editora da Unicamp, Imprensa Oficial do Estado de São Paulo, 2010.

VALÉRY, Paul. Degas Dança Desenho. São Paulo, Cosac \& Naify, 2003.

VASARI. Vidas dos Artistas/ Georgio Vasari; edição de Lorenzo Torrentino; organização de Luciano Bellosi e Aldo Rossi; apresentação de Giovanni Previtali; tradução de Ivone Castilho Benedetti - São Paulo: Editora WMF Martins Fontes, 2011.

VESSALIUS, Andrea. De Humani Corporis Fabrica. Epitome. Tabula Sex. São Paulo, Ateliê Editorial; Imprensa Oficial do Estado; Campinas, Editora da Unicamp, 2002.

WESTHEIM, PAUL. El Grabado en Madera. Mexico D.F.: Fondo de Cultura Economica, 1992.

WYE, Deborah. Thinking Print: books to billboards, 1980-95. New York: The Museum of Modern Art, 1996. 


\section{Agradecimentos}

Ao meu orientador, Marco Buti, pelo olhar atento e precisas palavras.

Ao Instituto Brasileiro de Museus, pela licença concedida para a conclusão de meu trabalho.

A toda equipe do Museu Lasar Segall, e particularmente ao diretor Jorge Schwartz e ao chefe de divisão técnica Marcelo Monzani, pelo apoio a esse projeto.

Ao Grupo de Pesquisa em Impressões Fotográficas, especialmente a seu coordenador, João Musa, por todo aprendizado e troca de conhecimentos e experiências.

A Adriane Bertini, pelo trabalho conjunto no projeto gráfico.

A Carolina Coutinho, pela revisão do texto.

A Christina Borten, pela revisão do abstract.

A toda minha família, em especial a Gisa e Antonio, pelo companheirismo e paciência.

Dedico este trabalho à memória de meu pai, Manoel. 
fonte Avenir

papel Munken Lynx Rough 120g/m² e Pólen Bold 90g/m² pré impressão e impressão IPSIS

tiragem 15 
